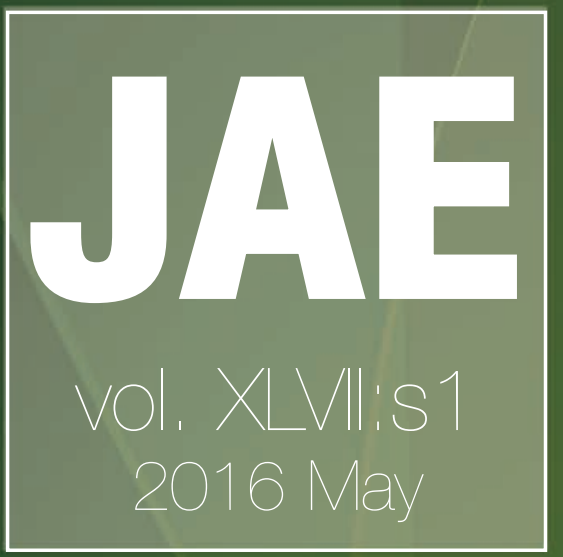

Official Journal of the Associazione Italiana

di Ingegneria Agraria

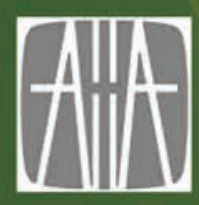

\title{
Mechanization and new technologies for the control and the sustainability of agricultural and forestry systems
}

Alghero, Italy, 29th May - 1 ${ }^{\text {st }}$ June 2016

\section{Journal of Agrricultural Engineering}




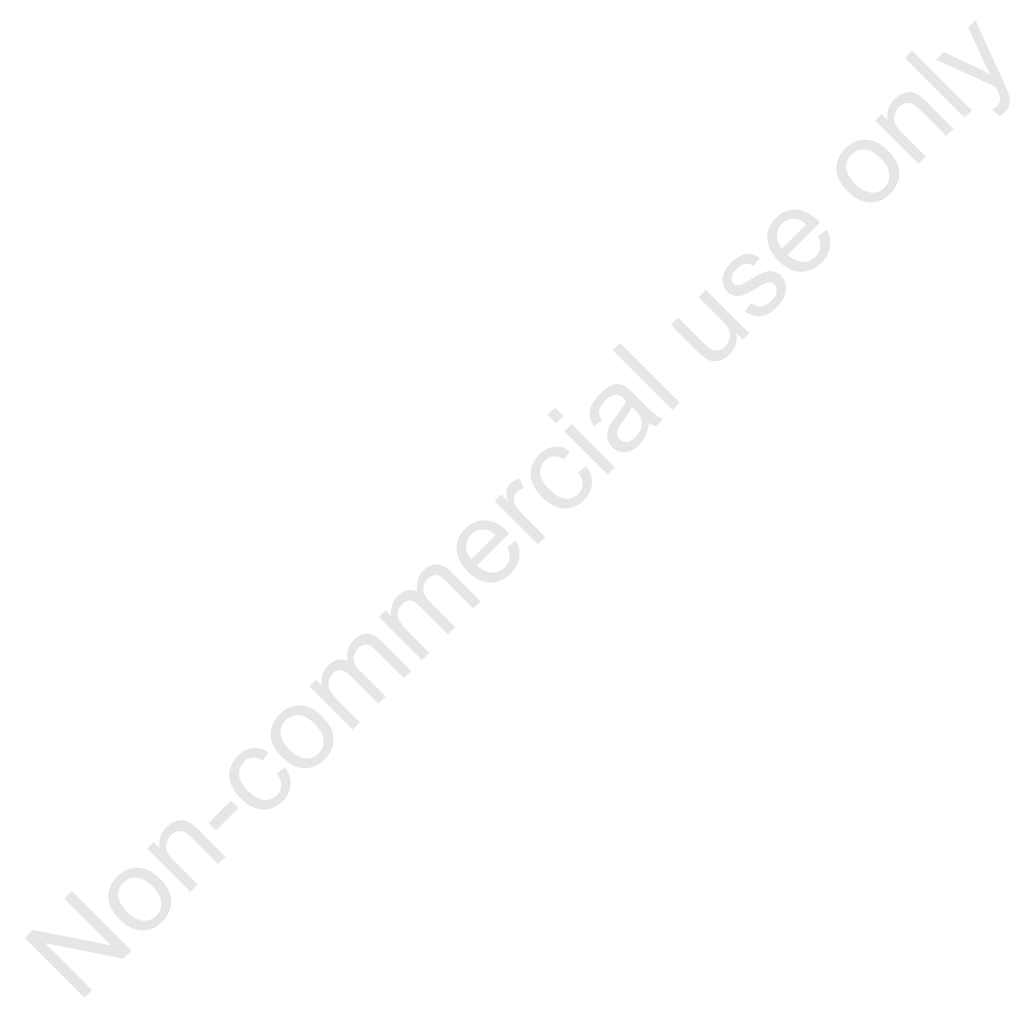




\section{Journal of Agricultural Engineering}

pISSN 1974-7071 | eISSN 2239-6268

\section{Editor-in-Chief}

Giovanni Molari, Department of Agricultural and Food Sciences, University of Bologna, Viale G. Fanin, 50, 40127 Bologna, Italy E-mail: giovanni.molari@unibo.it

\section{Associate Editors}

Paolo Balsari, University of Torino, Italy

Claudio Gandolfi, University of Milano, Italy

Giacomo Scarascia-Mugnozza, University of Bari "Aldo Moro", Italy

\section{Editorial Board}

Pedro Aguado, University of Leon, Spain

Juan Ángel Mintegui Aguirre, Polytechnic University of Madrid, Spain

Francisco Ayuga Téllez, Polytechnic University of Madrid, Spain

Demetres Briassoulis, Agricultural University of Athens, Greece

Artemi Cerdà, University of Valencia, Spain

Giancarlo Colelli, University of Foggia, Italy

Josse Debaerdemaeker, Catholic University of Leuven, Belgium

Salvatore Di Fazio, Mediterranean University of Reggio Calabria, Italy

Istvan Farkas, Gödöllo University of Agricultural Sciences, Hungary

Vito Ferro, University of Palermo, Italy

Emilio Gil, Polytechnic University of Catalunya, Spain

Valentin Golosov, Moscow State University, Russia

Dirk Jaeger, University of Freiburg, Germany

Pavel Kic, University of Life Sciences Prague, Czech Republic

Andrew Landers, Cornell University, USA

Attila Nemes, BIOFORSK, Norwegian Institute for Agricultural and Environmental Research, Norway

George Papadakis, Agricultural University of Athens, Greece

Giovanni Luca Riva, Polytechnic University of Marche, Italy

Nunzio Romano, University of Napoli, Italy

Masoud Salyani, University of Florida, USA

María Teresa Sánchez-Pineda, University of Córdoba, Spain

Daniel M. Tartakovsky, University of California, San Diego, USA

Patrizia Tassinari, University of Bologna, Italy

Arnold van der Valk, Wageningen University, the Netherlands

Henrik Vejre, University of Copenhagen - LIFE Faculty of Life Sciences, Denmark

M.J. Whelan, Cranfield University, UK

\section{Editorial Staff}

Paola Granata, Managing Editor

Cristiana Poggi, Production Editor

Tiziano Taccini, Technical Support

\section{Publisher}

PAGEPress Publications

via Giuseppe Belli 7

27100 Pavia, Italy

Tel. +39.0382 .464340 - Fax. +39.0382 .34872$

info@pagepress.org - www.pagepress.org 


\section{Journal of Agricultural Engineering}

The Journal of Agricultural Engineering (JAE) is the official journal of the Italian Society of Agricultural Engineering - AIIA - supported by University of Bologna. The subject matter covers a complete and interdisciplinary range of research in engineering for agriculture and biosystems.

\section{Instructions to Authors}

Manuscripts must be written in English. Authors whose native language is not English are strongly recommended to have their manuscript checked by a language editing service, or by an English mother-tongue colleague prior to submission.

Manuscripts should be saved and submitted as a single WORD file containing the full text, references, tables and figures. In case of acceptance, original text and figures must be provided for publication.

Original Articles: should normally be divided into an abstract, introduction, materials and methods, results, conclusions and references (max. 5/7 figures and/or tables). The abstract should contain a maximum of 400 words. Review Articles: no particular format is required for these articles (max. 5/7 figures and/or tables). However, they should have an informative, unstructured abstract of about 250 words. Technical Notes: are articles with a simple layout and containing limited data (no more than two figures or tables) and a small number of citations (not more than 25). They should be limited to 2,000 words of text (figure captions, table headings and reference lists are additional to this limit).

Manuscripts should be double spaced with numbered lines and wide margins and should be arranged as follows. Title page: including the full title, the name(s) of the author(s), their affiliation and the name of the corresponding author to whom proofs and requests for off-prints should be sent. Abstract: should not exceed 400 words Keywords: three to six keywords characterizing the content of the article in alphabetical order. Introduction: A brief introduction. Materials and methods: this section should provide sufficient information and references on the techniques adopted to permit their replication. Results: the content of this section should permit full comprehension of the data reported in figures and tables. Conclusions: this should underline the significance of the results and place them in the context of previous research. Acknowledgements: a brief text. References should be prepared strictly according to the instructions given below. Units: authors are recommended to use the International System of Units (SI). Scientific names: common names of organisms should always be accompanied, when first cited, by their complete scientific name in italics (genus, species, attribution and, if appropriate, cultivar). Formulae: mathematical formulae must be carefully typed, possibly using the equation editor of Microsoft Word; when a paper contains several equations they should be identified with a number in parentheses (e.g. Eq. 1). Please note that each accepted paper will undergo technical and scientific copyediting before publication. Tables: tables are numbered consecutively in Arabic numbers without "no." before the number. References should be made in the text to each table. The desired style of presentation can be found in published articles. Titles of tables should be descriptive enough to be able to stand alone. Do not present the same data in tabular and graphic form. Figures: figures are numbered consecutively in Arabic numbers. References should be made in the text to each figure. Each figure should have a caption. The term "figure" is used also for graphs and photos. Symbols and abbreviations used in figures can be defined in the figure caption or note or within the figure itself. Please avoid the use of bold face or greater size for the characters. Symbols and abbreviations used in figures can be defined in the figure caption or note or within the figure itself. The figures must be submitted as .tif or .jpg files, with the following digital resolution: 1. Color (saved as CMYK): minimum 300 dpi; 2. Black and white/grays: minimum $600 \mathrm{dpi}$; Lettering of figures must be clearly labelled. Movies: movies can be submitted and uploaded as "Supplementary Files" during the manuscript submission procedure. Dimension should not exceed 5 MB. Citations in the text: the Journal follows the "author, year" style of citation. When a citation has one or two authors, cite the reference throughout using the name(s) and the date. When a citation has more than two authors, cite the reference throughout the text with et al. following the last name of the first author. When two or more references are included in a grouping within a sentence, they are arranged and separated by a semicolon. The first criterion is the year (former citations precede recent ones); multiple citations for a given year are further arranged alphabetically and multiple citations for the same initial letter are arranged as follows: first the citation with one author, secondly the citation with two authors, then the other (with et al.). When the same author has two references with different dates, cite them in chronological order, separating the dates with a comma; when the same author has two references with the same date, arrange the dates as a and $b$ (also in the reference list) and separated by a comma. Journal titles mentioned in the reference list should be abbreviated according to the following websites (sequenced by relevance): 1. ISI Journal Abbreviations Index (http://library.caltech.edu/reference/ abbreviations/); 2. Biological Journals and Abbreviations (http://home.ncifcrf.gov/research/bja/) Example: (Foury, 1967, 1972; Burns et al., 1970; Allen et al., 1990; Basnizki and Zohary, 1994; White et al., 1990a, 1990b). Citation should be made in the text to each reference. Citations are listed in strict alphabetical order by first author' last names. Use capital and lower case letters for authors' names. If all authors are identical for two or more citations, chronological order of publication should dictate the order of citations. When more than one paper in a given year is listed by authors whose names are in the same order in each paper, the papers are arranged in alphabetical order of the paper title. Use the following system to arrange your references:

1. Periodicals: Hennighausen L.G., Sippel A.E. 1982. Characterization and cloning of the mRNAs specific for the lactating mouse mammary gland. Eur. J. Biochem. 125:131-41.

2. Books: National Research Council 2001. Nutrient Requirements of Dairy Cattle. 7th rev. ed. National Academy Press, Washington, DC, USA.

3. Multi-authors books: Brouwer I. 1965. Report of the subcommittee on constants and factors. In: K.L. Blaxter (ed.) Energy metabolism. EAAP Publ. N. 11, Academic Press Ltd., London, UK, pp 441-3.

4. Proceedings: Rossi A., Bianchi B. 1998. How writing the references. Proc. 4th World Congr. Appl. Livest. Prod., Armidale, Australia, 26:44-6. (Or 44, if one page) -

Blanco P., Nigro B. 1970. Not numbered volumes. Page 127 (or pp 12-18) in Proc. 3rd Int. Conf. Cattle Dis., Philadelphia, PA, USA. 
5. Thesis: Rossi P. 1999. Stima di parametri genetici nella razza Reggiana. Degree Diss., Università di Milano, Italy.

6. Material from a World Wide Web site: Food and Drug Administration, 2001. Available from: http://www.fda.gov or Food and Drug Administration, 2001. http:/www.fda.gov Accessed: May 2012.

7. Regulations:

- Italian Regulation, 1992. Application of the Council Directive (EEC) No. 86/609 regarding the protection of animals used for experimental and other scientific purposes. LD 116/1992. In: Official Journal No. 294, 18/2/1992, pp 5-24.

- European Commission, 1994. Commission Decision of 27 June 1994 concerning certain protection measures with regard to bovine spongiform encephalopathy and the feeding of mammalian derived protein, 94/381/EC. In: Official Journal, L 172, 07/07/1994, pp 23-24.

8. International standards: ISO, 1991. Determination of total fat content - Meat and meat products. Norm ISO R1443:1991. International Organization for Standardization Publ., Geneva, Switzerland.

9. In press: Manuscripts that have been accepted for publication but are not yet published can be listed in the literature cited with the designation [In press] following the journal title.

10. Other: Citations such as personal communication, unpublished data, etc. should be incorporated in the text and NOT placed into the Reference section.

\section{Copyright}

All material published by PAGEPress Publications, whether submitted to or created by PAGEPress, is published under an Open Access license that lets others remix, and build upon your work non-commercially, and although their new works must also acknowledge you and be non-commercial, they don't have to license their derivative works on the same terms.

PAGEPress strives to set the highest standards of excellence in all aspects of its activities, whether this be its journal image, its style of presentation, the quality of the editorial process at every level, the transparency of its operations and procedures, its accessibility to the scientific community and the public, and its educational value.

PAGEPress welcomes and actively seeks opportunities to work together with any group (scientific/scholarly societies, physicians, patient advocacy groups, educational organizations) and any publisher who shares our commitment to Open Access and to making scientific information available for the benefit of science and the public good.

PAGEPress charges authors a price that reflects the actual costs of publication. However, the ability of authors to pay publication charges will never be a consideration in the decision as to whether to publish.

PAGEPress aims to be a truly international organization by providing access to the scientific literature to anyone, anywhere, by publishing works from every nation, and by engaging a geographically diverse group of scientists in the editorial process.

\section{Peer-review policy}

All manuscript submitted to our journals are critically assessed by experts in accordance with the principles of Peer Review, which is fundamental to the scientific publication process and the dissemination of sound science. Each paper is assigned to the Chief Editor. The first step of manuscript selection takes place entirely inhouse and has the objective to establish the article's appropriateness for our journals' readership. The articles are then reviewed by two different external referees (second step or classical peerreview) in accordig with the associate editors.

\section{Subscriptions}

Italy: $€ 65.00$ per year; one number: $€ 25.00$; back issues or double issues: $€ 25.82$; back year: $€ 72.30$

Abroad: annual subscription: $€ 75.00$ - air mail subscription: $€ 90.00$.

Autorizzazione Del Tribunale Di Bologna N. 4045 Del 3

Febbraio 1970

\section{Journal of Agricultural Engineering}

Rivista trimestrale registrata al Tribunale di Pavia n. 9/2012/Reg.

Press Up s.r.l.

via La Spezia, 118/C 00055 - Ladispoli (RM)

Phone and Fax: +39.076 .15 .27 .351$

Tutti gli articoli pubblicati su Journal of Agricultural Engineering sono redatti sotto la responsabilita degli Autori. La pubblicazione o la ristampa degli articoli della rivista deve essere autorizzata per iscritto dall'editore. Ai sensi dell'art. 13 del D.Lgs 196/03, i dati di tutti i lettori saranno trattati sia manualmente, sia con strumenti informatici e saranno utilizzati per l'invio di questa e di altre pubblicazioni e di materiale informativo e promozionale.

Le modalità di trattamento saranno conformi a quanto previsto dall'art. 11 del D.Lgs 196/03. I dati potranno essere comunicati a soggetti con i quali PAGEPress intrattiene rapporti contrattuali necessari per l'invio delle copie della rivista. Il titolare del trattamento dei dati è PAGEPress Srl, via Belli 7 - 27100 Pavia, al quale il lettore si potrà rivolgere per chiedere l'aggiornamento, l'integrazione, la cancellazione e ogni altra operazione di cui all'art. 7 del D.Lgs 196/03.

Supported by the Alma Mater Studiorum University of Bologna

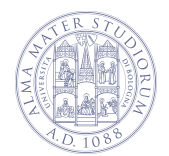

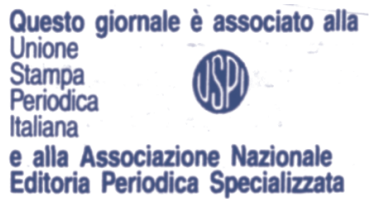




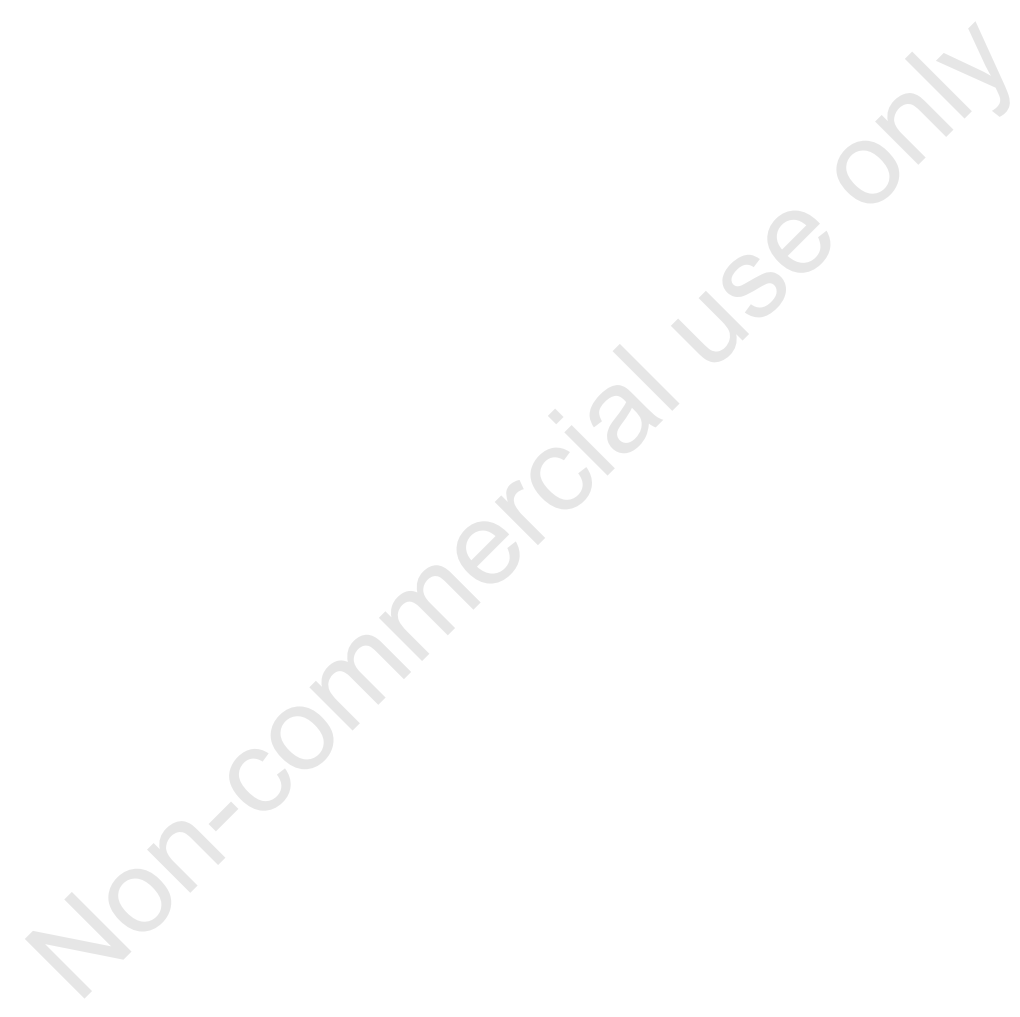




\section{Journal of Agricultural Engineering volume XIVII, supplement 12016}

\section{Mechanization and new technologies for the control and the sustainability of agricultural and forestry systems}

Alghero, Italy, 30 $30^{\text {th }}$ May - $1^{\text {st }}$ June 2016

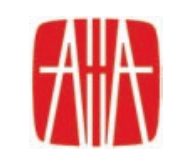

Table of Contents

Innovative solutions for the mechanization of agricultural and forestry systems .............1

Technologies for reducing the environmental impact of agricultural and livestock productions
Work organization, logistics and quality in agricultural and forestry sectors

Sustainability of energy uses in agricultural and forestry systems .0 .24

Modeling and automation for process precision management. .13 


\section{ScIENTIFIC CommitTeE}

Antonio Luigi Pazzona, Chairman, Università di Sassari Danilo Monarca, Presidente AIIA

Giovanni Molari, Editor in Chief of JAE

Raffaele Cavalli

Marco Vieri

Paolo Balsari

Ester Foppa Pedretti

Giampaolo Schillaci

Remigio Berruto

Giancarlo Colelli

Riccardo Guidetti

Guido D’Urso

Fabrizio Mazzetto

Lelia Murgia

Sandro Liberatori, Direttore Enama

Paolo Menesatti, Presidente CRA Ing

\section{Organizing Committee}

Antonio Luigi Pazzona

Lelia Murgia

Filippo Gambella

Maria Caria

Giuseppe Todde

Giovanni Chessa

\section{Organizing Secretariat}

Dipartimento di Agraria - Sez. Ingegneria del territorio mechtech2016@uniss.it

Tel. +39.079.229375 - Fax +39.079.229285 


\section{Journal of Agricultural Engineering 2016; volume XLVII(s1)}

\section{INNOVATIVE SOLUTIONS FOR THE MECHANIZATION OF AGRICULTURAL AND FORESTRY SYSTEMS)}

\section{CONCEPT OF AN INNOVATIVE TILTABLE PLATFORM FOR THE EXPERIMENTAL TEST OF THE STABILITY OF AGRICULTURAL MACHINERY}

Marco Bietresato, Fabrizio Mazzetto

Libera Università di Bolzano, Facoltà di Scienze e Tecnologie, Bolzano, Italia

\section{E-mail:marco.bietresato@unibz.it}

Key words: innovative tiltable platform, stability of agricultural machinery, static and dynamic stability tests, circular path on a slope.

Current systems used to test the rollover stability of agricultural machines are simple albeit effective in their way of operating. They renounce to identify in detail the position of the centre of gravity but, rather, investigate the static performance of a vehicle in a condition as close as possible to the reality: the vehicle to be tested, equipped with its own tires, is placed on a tiltable flat platform and the angle of the platform necessary to have a side overturning of the vehicle is identified. This system has some limits: vehicles are tested under static conditions at the side overturning only, with their steering members (wheels, central joint) in a configuration corresponding to a straightpath travelling.

Therefore, this paper is intended to present a new equipment for testing the stability of machines, able to overcome the limitations of current systems. For its development, a "top-down" logic was followed: starting from some macro-requirements, the attention was focused on aspects of this system with an increasing level of detail and on smaller and smaller parts, expressing the minimum technical requirements that the various subsystems must have.

In particular, with the aim of having evidences as close as possible to those ones normally experimented by employees in their everyday practice, the design process started from the need to use the new platform for the following (completely new) tests:

- stability evaluation of a vehicle having its longitudinal axis angled with respect to the maximum slope direction of the support surface and, in particular, eventually engaged in a steering manoeuvre;

- stability evaluation of a vehicle engaged in a steering manoeuvre while entering/exiting from an interrow, therefore with a change of slope in the trajectory, however circular;

- lateral overturning evaluation of a vehicle in dynamic conditions, i.e. while steering on the platform at different speeds.

The turning manoeuvre is always critical for the safety: the steering wheels (for traditional vehicles) or the two halves (for articulated vehicles) are angled and the supporting polygon is modified.

Based on the requirements expressed here, the system will be therefore provided with a wide tilting plane (approximately $15 \mathrm{x} 15 \mathrm{~m}$ ) allowing a vehicle, eventually equipped also with a trailer, to travel on it along a complete circular trajectory. The tangent line at each point of this circumferential trajectory has a different inclination, comprised in particular between $-180^{\circ}$ and $+180^{\circ}$ with respect to the maximum slope direction of the platform.

The same support surface will have an articulation hinge, positioned at the centre of the supporting surface and having an extension equal to the platform width. This hinge will allow to angle the two flat parts that concur in it and on which the vehicles are placed and made travel: therefore, thanks to it, it will be possible to create an edge similar to a change in the slope.

Once completed, this platform will be part of the permanent equipment of the "Agroforestry Innovation Laboratory" of the Free University of Bolzano, located at the upcoming "NOI - Technology Park".

\section{DEVELOPMENT AND TESTS OF A VARIABLE RATE SYSTEM FOR THE DISTRIBUTION OF LIVESTOCK SLURRY WITH PRESSURIZED TANKERS}

Aldo Calcante, ${ }^{1}$ Roberto Oberti, ${ }^{1}$ Massimo Brambilla, ${ }^{2}$ Carlo Bisaglia ${ }^{2}$

${ }^{1}$ Dipartimento di Scienze Agrarie e Ambientali, Università degli studi di Milano; ${ }^{2}$ CREA-ING Unità di Ricerca per l'Ingegneria Agraria, Treviglio (BG), Italia

E-mail: aldo.calcante@unimi.it

Key words: Variable-rate distribution, Pressurized Slurry tankers, Precision agriculture, Slurry spreading control.

As is known, effluent management has become increasingly important among livestock farming activities because of: i) the need to valorise a sub-product with a high fertilizing potential, ii) the high costs associated with spreading operations, and iii) the environmental impacts that could result from inadequate effluent management at the farm level. Due to this issue, the European Commission issued several Directives aimed at protecting the environment while ensuring that farmers could achieve proper production levels. In particular, Directive $91 / 676 / \mathrm{EC}$ is currently the main regulation aimed at protecting water from nitrate accumulation due to farming operations. Due to this directive, nitrate vulnerable zones have been set with strict regulations regarding the timing and rates of nitrogen application in these zones. In the vulnerable zones, a specific threshold limits the application rate to $170 \mathrm{~kg} / \mathrm{ha}$ per year for nitrogen whilst, in the remaining areas, the threshold is $340 \mathrm{~kg} / \mathrm{ha}$.

The present study aimed to develop a variable-rate (VRT) system, including electro-mechanic components, capable of automatically controlling the nitrogen distribution rate in the open field. The VRT system was specifically designed for pressurized slurry tanker, i.e., equipped with a vacuum/pressure pump (the most diffused spreading technology used in Italy), and according to a "retrofit" logic as a selfstanding module that can be adapted and mounted on existing pres- 
surized slurry tanker equipment. Moreover, this system can work with any distribution system, including a spreader plate, crawling nozzles, soil injectors, etc. For field-testing purposes, this system was mounted on a double-axis $10 \mathrm{~m}^{3}$ slurry tanker equipped with a crawling nozzle distribution unit. Field experiments were conducted at two typical forward speeds (2 and $3 \mathrm{~km} / \mathrm{h}$ ) and three different nitrogen application rates $(170,250$, and $340 \mathrm{~kg} / \mathrm{ha})$. Based on the experimental results, the system was generally capable of limiting the differences between the nominal and measured application rates to less than $9 \%$. In addition, the data analysis indicated that the slurry spreading was not significantly affected by the forward speed of the tanker. Finally, the uniformity of nitrogen spreading was evaluated according to the UNI EN 13406:2002 standard. The results showed that the transverse field distribution was uniform throughout the working width of the machine and at all tested operating conditions, with maximum deviations that were limited to less than 15\% (limit value imposed by UNI standard).

\section{REAL-TIME MILK ANALYSIS AND SEPARATION IN MILKING PARLORS: PRELIMINARY SURVEY}

Maria Caria, Giuseppe Todde, Lelia Murgia, Luisella Sistu, Marco Pinna, Antonio Pazzona

\section{Dipartimento di Agraria, Università degli Studi di Sassari, Italia} E-mail:mariac@uniss.it

Key words: milk quality, online measurement, cheese.

The aim of this work was to evaluate the efficiency of real time milk separation during cow's milking through the use of the Afimilk MCS (Milk Classification Service). The study were carried out in three conventional dairy farms located in the Arborea (Oristano) area, where in existing milking parlors were installed the Afimilk MCS devices to analyze and separate milk of each milked cow. The Afimilk MCS analyzed the milk through the Afilab ${ }^{\text {TM }}$ (S.A.E. Afikim, Israel), a spectrometer that works in real-time and performs measurements of milk's components. The Afilab ${ }^{\mathrm{TM}}$ were installed in the milking parlor, next to the milk meter, one for each station. The tool becomes an integral part of the system, allowing to analyze the milk of each animal in the herd at every milking. The analysis of Afilab ${ }^{\mathrm{TM}}$ is based on near-infrared spectroscopy; during milking, the milk of a bovine (each $200 \mathrm{~g}$ ) is traversed by a ray of light and Afilab ${ }^{\mathrm{TM}}$, reading the refraction of light striking the milk, it is able to determine the content of fat, protein, lactose and somatic cells.

The installation of the Afimilk MCS system has proceeded to modify the pre-existing milking parlors with an additional milk pipeline, to allow the conveying of the two types of milk (concentrated fraction and poor fraction), in the two different cooling tanks. The concentrated fraction is milk suitable for the production of soft cheeses (due to the higher content of fat and protein), while poor fraction is used as drinking milk. After the installation of the Afimilk MCS a calibration period of 10-20 days have been done for each of the three dairy farms. From May to September 2015 about 200 samples of separated milk were tested and analyzed by the ARAS (Associazione Regionale Allevatori Sardegna) laboratories. The separation tests were carried out by calibrating the system Afimilk MCS with three different levels of separation to identify the best combination between the quantity and quality of the separated milk: $40 \%$ concentrated fraction and $60 \%$ poor fraction; $50 \% / 50 \% ; 70 \%$ concentrated fraction and $30 \%$ poor fraction. At each level of separation there was an increase in the content of fat and protein in the milk of the concentrated fraction. The milk separation level with a better relationship between quality and quantity of the components of the milk was found to be the one being set to $50 \%$. The results obtained for this level of separation showed, for the concentrated fraction, a fat content from $4.78 \%$ to $5.00 \%$ and from $2.50 \%$ to $2.67 \%$ of the poor fraction. As it regards the content of protein were observed the following range of values: $3.28 \%-3.36 \%$ for the concentrated fraction and $3.05 \%$ to $3.09 \%$ for the poor fraction.

\section{A PORTABLE DEVICE FOR ESTIMATING THE SOMATIC CELL COUNT IN SHEEP MILK}

Giovanni Chessa, Maria Caria, Filippo Gambella, Antonio Pazzona

\section{Dipartimento di Agraria, Università degli Studi di Sassari, Italia}

E-mail: giovachessa@uniss.it

Keywords: electrical conductivity, ion sodium, software, animal welfare.

Somatic cell count (SCC) represents a marker to monitor the udder health in dairy ruminants. In a situation of non-specific illness, such as infections by microorganisms, shocks and/or injuries to the breast tissue, improper milking and environmental stress, the immune system sends in the breast the white blood cells and, consequently, milk presents an increase in SCC. An indirect method widely used for the estimation of the somatic cells is the measurement of the milk electrical conductivity (EC). The value of EC depends on several factors including the iones $\mathrm{Na}^{+}, \mathrm{K}^{+}$and $\mathrm{Cl}$, which represent, in addition to lactose, the osmotically active components of milk. Portable and online EC meters are commercially available, however the correlation between EC and SCC is low both in sheep $\left(R^{2}=0.37\right)$ and cow milk $\left(R^{2}=0.39\right)$.

The objective of this work was to study the relationship between the ione $\mathrm{Na}^{+}$and the main components of sheep milk, in particular somatic cells. Moreover, a portable device for estimating SCC in sheep milk was designed. The study was conducted on 75 Sarda breed sheep, randomly selected from three different farms located in Sardinia (Italy). A weekly sample of $50 \mathrm{ml}$ of milk was taken from each half udder during the morning milking. Sampling lasted from March to June 2015, and a total of 1,500 samples were analyzed.

The milk components examined were: fat, proteins, lactose, $\mathrm{pH}$, sodium chloride, urea (Milkoscan FT 6000, Foss Electric, Hillerød, Denmark), SCC (Fossomatic 5000, Foss Electric, Hillerod, Denmark) and the ions $\mathrm{Na}^{+}$(Laquatwin B725, Horiba, NY, USA) in the ARA (Associazione Regionale Allevatori) certified laboratory (Oristano, Sardinia). Arithmetic means, standard deviations and Pearson correlation coefficients were calculated on the parameters. Values of SCC were transformed into natural logarithm to determine the relationship between sodium ions and SCC. The correlation between $\mathrm{Na}+$ and SCC corresponded to $\mathrm{R}^{2}=0.76(\mathrm{P}<0.001)$.

The prototype developed incorporates two containers which receives milk samples taken from each half udder. Each container has integrated inside two sensors, one to detect the level of $\mathrm{Na}^{+}$in the milk and the other one to compensate the milk temperature. The mathematical model, loaded into the microcontroller by a firmware written in $\mathrm{C}$ / $\mathrm{C}$ ++ , analyze the data and gives back the estimate of SCC level. The device is also equipped with a slot for memory card (SD card) that allows to storage the measured data. The portable device developed would allow farmers and stakeholders to monitor the ewes health status by periodically comparing the somatic cell counts of each half udder. 


\section{TECHNIQUES AND MACHINES FOR CONSERVATION AND ORGANIC AGRICULTURE: THE S.M.O.C.A. PROJECT}

Christian Frasconi, ${ }^{1}$ Daniele Antichi, ${ }^{1}$ Marco Fontanelli, ${ }^{1}$ Luisa Martelloni, ${ }^{1}$ Michele Raffaelli, ${ }^{1}$ Michel Pirchio, ${ }^{1}$ Giacomo Tosti, ${ }^{2}$ Luigi Manfrini, ${ }^{3}$ Aurelio Pristeri, ${ }^{4}$ Simona Bosco, ${ }^{5}$ Andrea Peruzzi ${ }^{1}$

${ }^{1}$ Dipartimento di Scienze Agrarie, Alimentari e Agro-ambientali, Università di Pisa; ${ }^{2}$ Dipartimento di Scienze Agrarie e Ambientali, Università degli Studi Perugia; ${ }^{3}$ Dipartimento di Scienze Agrarie, Università di Bologna; ${ }^{4}$ Dipartimento di Agraria, Università degli Studi di Reggio Calabria; ${ }^{5}$ Istituto di Scienze della Vita, Scuola Universitaria Superiore Sant'Anna, Pisa, Italia

\section{E-mail: christian.frasconi@unipi.it}

Key words: cover crop, no tillage, weed management, conservation agriculture.

The combination of low environmental impact farming techniques and conservation agriculture techniques is considered not feasible due to some limitations, mainly including is the strong dependence of conservation cropping systems by chemical control of weeds and the use of mineral fertilizers, which are considered essential for supporting to acceptable levels of crop productions.

In order to apply the techniques of reduced tillage also in organic and integrated agriculture, is therefore indispensable, on one hand, the availability of specific versatile and efficient machines for non-chemical cover-crop management, weed control and sod-seeding/planting, on the other hand, the optimization of cropping systems in function of improved nutrient cycling and preventive weed control.

The SM0CA project (Smart Management Conservation of Organic Agriculture) aims to integrate organic cropping systems and conservation agriculture techniques in three different scenarios (arable open field, open field vegetables and orchards) thanks to development of machines and technical itineraries that allow to apply the reduced tillage techniques even in the absence of pesticides.

Within this project, prototypes of machines were realized in order to implement conservation cropping systems with high energy efficiency.

For each scenario, three technical itineraries were compared:

- control (INT): based on integrated agriculture without use of conservation agriculture techniques. The use of agrochemicals is allowed in accordance with the disciplinary for integrated production;

- organic system (ORG): based on the organic agriculture, involves the use of cover crops (managed as green manure) and soil tillage. The non chemical management of weed flora is achieved with preventive methods and direct methods (mechanical and thermal weed control);

- organic and conservation system (ORG +): based on the deep integration between the principles of conservation agriculture and organic farming. The system aims to achieve an almost continuous coverage of the soil through the use of no-tillage techniques and cover crops managed as living or dead mulches.

The study of the overall sustainability of the different systems in comparison is conducted by means of a detailed analysis of the following aspects:

- agronomic;

- energy and environmental;

- economic.

The environmental effect of the compared systems will be mainly assessed through the study of the following aspects: greenhouse gas emissions, nutrient balance, preservation of soil quality, biological nitrogen fixation, conservation of water resources in the soil and the life cycle assessment (LCA). The efficiency and the impact of different management techniques are also continuously monitored on the orchard and vegetable crops through the study of the fruits of growth dynamics, thanks to an innovative methodology that uses a network of growth sensors spatially distributed in the field. The final product quality is also evaluated through the analysis of their levels of nutraceutical compounds. The research project is still ongoing and the prototypes of machines realized are presented in this paper.

\section{NEW METHODOLOGICAL APPROACH FOR OPERATIONAL MONITORING OF CHAINSAW FOR THE MOTOR MANUAL FELLING OPERATIONS: PRELIMINARY RESULTS}

\section{Raimondo Gallo, Fabrizio Mazzetto \\ Libera Università di Bolzano, Facoltà di Scienze e Tecnologie, Italia E-mail: raimondo.gallo@unibz.it}

Key words: time study, productivity, information system, ICT, Precision Forestry.

The present work shows the preliminary results obtained by the application of an innovative approach for the operative monitoring of the entire logging chain. This work focusses on a new proposal of innovative solution (software and hardware) of Precision Forestry, which can be employed as information system for the management of the forest companies. In general, the proposed system will be able to manage operational information as: i) the positioning, the measurement of the tree's diameter and the estimation of the volume of the tree that will be cut ii) the automatic monitoring of the felling operation performed with the chainsaw, iii) the automatic monitoring of the logging activities from the felling site to the storage. The employment of this system will allow to obtain operative information for the compilation of the register of activity, suitable to be used for the certification and traceability process as well as for the estimation of the operative costs.

The preliminary analysis has taken into account the operations performed with the use of chainsaw. The operational parameters, which characterized the productivity of felling operations through chainsaw, have been monitored thanks to the use of dedicated ICT devices. In order to detect the phases that compose the felling operation, it has been considered that the lumberjack during the effective cutting drives the chainsaw with the engine with the highest rpm. In this condition the vibration generated by the machine reaches the maximum amplitude. Therefore, assessing the duration of the vibration with the maximum amplitude, it is possible to define the effective time and the surface interested by the cut since these variables are proportional.

The experiment was conducted in a controlled environment, where a professional chainsaw (Husqvarna $560 \mathrm{SP}$ ) was equipped with a triaxle accelerometer. The accelerometer was installed on the upper part of the chainsaw and it was set with a sampling frequency of $1 \mathrm{kHz}$.

Three vertical cuts and one which reproduce the actual felling cut (backcut+undercut) were carried out on seven logs with different diameters. During the cutting a manual time study were performed in order to validate the estimation obtained by the proposed approach.

The preliminary analysis of the results highlighted that the application of an accelerometer on the chainsaw is a good and interesting solution for the assessment of both the time study and the surface interested by the cutting. In conclusion, the tested device can be considered as a tool of Precision Forestry only if it will be possible to integrate it in a hardware with small dimension in order to avoid stress to the operator during his activities. 


\section{OPTIMIZING THE WOOD SUPPLY CHAIN IN CALABRIA}

Giorgio Macria, Andrea Rosario Protoa and Zimbalatti Giuseppea

Mediterranean University of Reggio Calabria, Department of Agraria, Feo di Vito, Reggio Calabria, Italy

E-mail: giorgio.macri@unirc.it

Key words: wood, extraction, mechanization, non-destructive test, wood supply chain.

Calabria is a region in Southern Italy with a forest cover equal to $31.8 \%$. Despite such a conspicuous density of woodland resources, the most common working method in Calabria, can be considered as begin traditional and at an early stage of mechanisation. It is based mainly on agricultural tractors, sometimes with specific forest machines like winches, hydraulic cranes, log grapples but also, the use animal for gathering and yarding is a widely used technique. Starting from these consideration, the main purpose of this research is to look into the reality of forest utilizations, with a special attention to the study of the mechanization level used in forest utilizations. The second important object was to determine the quality of wood assortments using acoustic technologies. This method presents the fundamentals of acoustic wave in tress propagation in trees and logs and discusses two different mechanism of acoustic velocity measurement, time of flight (TOF) approach for standing trees and resonance - based approach for logs. The research activity were conducted in two different sites: Serre massif (VV) and Sila massif (CS). In these areas we evaluated site productivity and site quality by using different technology:

1. Productivity by using innovative forestry machine (Skidder);

2. Wood quality by using a non-destructive technologies (Tree Sonic).

Productivity was detected in a study areas located in Brognaturo (VV) at about $1200 \mathrm{~m}$ above sea level, in a chestnut forest, Serre Vibonesi mountain. The area was divided in site A and site B on the basis of the different technology used. During the skidding operations the machine (Skidder John Deere) operates was constantly monitored and the various distances were noted down. The total number of logs were counted and transported to calculate the volume of each load to obtain a good estimate of the total volume transported. A regression equation was developed for the total cycle time, and the results indicated that the total cycle time was related to the skidding distance and the number of logs per turn. A small diameter of felled trees leaded to an increase in their number in each turn and also in winching time.

The study of wood quality by non-destructive technologies were conducted in a Calabrian pine plantation of 60-year, located in Varco San Mauro (Cosenza). The study area consisted of four plots, each under different treatments: Control (T - 1200 plants/ha), light thinning (A 800 plants/ha), intermediate thinning (B - 600 plants/ha), and heavy thinning (C - 400 plants/ha). Wood quality with non-destructive technologies have been calculated using the acoustic velocity estimated by the FAKOPP Tree Sonic ${ }^{\mathrm{TM}}$. The acoustic velocity was subsequently calculated from the span between the two sensor probes and the TOF data using $(\mathrm{CT}=\mathrm{S} / \Delta \mathrm{T})$ where $\mathrm{CT}$ is tree acoustic velocity $(\mathrm{m} / \mathrm{s}), \mathrm{S}$ is distance between the two probes (sensors) (m), and $\Delta \mathrm{t}$ is time-of-flight (s). The differences among the four stands in Calabrian pine were distinguished in terms of stress wave time - the upper value was the speed registered using the time-of-flight methodology and lower was the value of wood stiffness estimated. The stress wave time average of trees in site A was about $5 \%$ higher than control site (T) while in site C (heavy thinning), the value was lower than control (at about 9\%). These results demonstrated that the effect of silvicultural practices on properties of wood can be successfully identified by stress wave MOEd.

\section{MONITORING OF THE OPERATING PARAMETERS OF AGRICULTURAL TRACTORS}

\author{
Michele Mattetti, ${ }^{1}$ Giovanni Molari, ${ }^{1}$ Eugenio Sereni ${ }^{2}$
}

${ }^{1}$ Department of Food and Agricultural Sciences, University of Bologna, Bologna, ${ }^{2}$ CNH Industrial Italy, Modena, Italy

Key words: Tractor, idling time, data logging, field test

During the last years methodologies for the definition of mission profile of vehicles and agricultural machines used by manufacturers for updating design and testing targets of new products, have been developed. Mission profile is usually defined by means of surveys, load measurements under specific conditions and hypothesis adopted by engineers. Among the latter, the total idling time is the most important, since it reduces the mission severity and a precise estimation allows manufacturers to design less robust machines with the same machine life expectancy. In this paper, a methodology to measure and analyse idling time usage from a fleet of agricultural tractors, is shown.

An onboard data-logger able to acquire and store the engine working parameters was installed on a fleet of tractors. Tractors were located in different countries and used for almost 800 hours in different tasks. The acquired data was statistically analysed in order to understand if the tractor location may affect the idling usage. From the results analysis, a dependency between total idling duration and tractors location was found. Especially, tractors located in areas with extreme temperatures run in idling condition for longer time to maintain the optimal engine temperature and cab thermal comfort during stops.

\section{EVALUATION OF SAFETY ASPECTS FOR A SMALL-SCALE MACHINE FOR NUTS HARVESTING}

Danilo Monarca, ${ }^{1}$ Massimo Cecchini, ${ }^{1}$ Andrea Colantoni, ${ }^{1}$

Roberto Bedini, ${ }^{1}$ Leonardo Longo, ${ }^{1}$ Walter Bessone, ${ }^{1}$

Luciano Caruso, ${ }^{2}$ Giampaolo Schillaci ${ }^{2}$

${ }^{1}$ Department of Agricultural and Forestry Sciences, University of Tuscia, Viterbo; ${ }^{2}$ Department of Agricultural Engineering, University of Catania, Italy

\section{E-mail:monarca@unitus.it}

Key words: Small scale mechanization, hazelnut, safety aspects.

Most of machines for nut harvesting on the market are characterized by a suction system placed over a cart, with wheels or tracks, pulled by a tractor. This solution, although effective and efficient in rational cultivation with planting distances specifically designed to allow the passage of agricultural vehicles, misses instead possibility of use in spontaneous mountain hazel, without a regular planting distance. Moreover, the steep slopes that usually occur in wild hazel, make impractical the maneuvers with the possibility of tractor overturning.

Simple mechanical solutions were recently introduced which consist in placing the harvesting suction system above small self-propelled trucks. Recent research has been conducted on risk assessment (overturning risk) during nut harvesting operations in sloping land and on aspects of noise emission. In this study were assessed, in addition to yard efficiency and working time, safety aspects of a machine made by a local craftsman, but that had a commercial success in the Sicilian area, particularly in the Nebrodi park, an area of considerable importance for hazelnuts in Sicily. The machine is characterized by a vacuum system placed on a self-propelled crawler to harvest nuts in sloping land and with soils corrected with very close terraces and not easy to reach for the traditional mechanization. In particular, attention was focused to aspects such as noise level and stability: the last evaluated by means of a tillable platform. Moreover the main health risks due to biomechanical overload (risk of WRMSDs - Work Related Muscle Skeletal 
Disorders) have been analyzed through the risk index assessment, with particular regard to the operators involved in harvesting and in manual handling of the product. Data analysis and evaluation of safety aspects will identify the machine's ability to meet the harvesting operations and any limitations in terms of safety.

\section{AUTOMATIC DETECTION OF POWDERY MILDEW IN GRAPEVINE: IMAGING APPROACHES FOR ACCURATE SENSING IN FIELD CONDITIONS}

Roberto Oberti, Aldo Calcante, Marcello Iriti, Emanuele Tona, Massimo Marchi, Paolo Tirelli

Dip. Scienze Agrarie e Ambientali (DISAA), Università degli Studi di Milano, Italia

\section{E-mail:roberto.oberti@unimi.it}

Key words: disease detection, multispectral imaging, grapevine, precision crop protection.

Powdery mildew (Erysiphe necator Schwein) is a major fungal disease for grapevine, and for other specialty crops as well as, causing severe damages to yield and quality of the produce.

This disease is thoroughly controlled by uniform fungicides spraying to vineyards, following a calendar that can easily result in ten to fifteen fungicide treatments conducted with application rates of 500-1000 $\mathrm{dm}^{3} /$ ha or higher. Nevertheless, since primary infections are not evenly diffused, but rather they emerge from discrete foci, there is an evident potential of benefits associated to the development technologies for high-precision crop protection, i.e. systems able to detect initial infection foci and to operate targeted treatments on them, instead of applying homogenous and unselective sprayings as currently done.

Thanks to its specific features, proximal optical sensing from tractor, or other field platform, is a major candidate technique to early detect infection foci in grapevine and other specialty crops with vertical canopy structure. In the case of powdery mildew infection, anyway, the sensitivity in detecting early symptoms can be largely limited by the combination of small dimensions, low density, and spatial arrangement of thin fungal structures. This paper illustrates some of the results obtained by the authors in different experiments conducted on grapevine's powdery mildew automatic detection by means of multispectral imaging (in green, red and near-infrared channels) and of hyperspectral imaging (in 450-900 nm); and it discusses the measurements approaches aimed to improve the accuracy of the detection in field conditions and the data analysis algorithms.

\section{THE OPEN FLAME "PYRO-DISINFECTION" AND "PYRO-WEEDING" HEAT TREATMENTS FOR THE SUSTAINABLE CULTIVATION OF LEAFY GREENS}

Mauro Pagano, ${ }^{1}$ Roberto Tomasone, ${ }^{1}$ Carla Cedola, ${ }^{2}$ Mirco Guerrieri, ${ }^{1}$ Giulio Sperandio, ${ }^{1}$ Marco Fedrizzi ${ }^{1}$

${ }^{1}$ Council for Agricultural Research and Economics, Agricultural Engineering Research Unit (CRA-ING), Monterotondo (ROME), Italy; ${ }^{2}$ Council for Agricultural Research and Economics, Fruit Tree Research Center, (CRA-FRU), Rome, Italy

\section{E-mail:mauro.pagano@crea.gov.it}

Key words: LPG flaming, leaf vegetables, minimum tillage, weed control, crop residue.

"Fresh-cut leafy vegetables" are horticultural crops grown for the production of ready-to-eat (RTE) bagged salads. In Italy specialized farms grow these crops mainly under protected cultivation, using high technical levels to ensure high-quality produce. To remunerate investments adequately, growers need to repeat many crop cycles throughout the growing season and the soil is repeatedly tilled to sow succeeding cycles. Soil preparation commonly involves primary tillage with spading and rototilling tools, incorporating previous crop residues and organic fertilizers, followed by secondary tillage to form suitable raised seed beds. This intensive tillage causes great soil disturbance, accompanied by degradation of soil structure and acceleration of soil organic matter mineralization. Plant health is also an important issue, the high planting density and the microclimatic features of the greenhouse may promote the development of plant diseases. Disease management is difficult because the production cycle is very short and few active substances are authorized for use. The adoption of wide crop rotations and other agricultural practices that interrupt cultivation, such as soil solarization or green manures, is not economically feasible in the greenhouse. The leaves are harvested at commercial maturity by cutting the stem above the soil level, but leaving the crown and the roots in place. The green residue is ordinarily incorporated in the soil, however such a practice should be avoided because plant pathogens survive on crop debris and inoculum may accumulate in the soil. Removing all crop residues after harvest is an effective management strategy to help prevent diseases from becoming established. Dedicated machinery and farm implements have been specifically developed for managing crop residue and for reducing tillage intensity. These machines combine the removal of crop residues and the use of "open flame" LPG burners, applying a thermal treatment that disinfects crop residues and the top layer of the soil, removing inocula and eliminating weed seeds. The integration of these mechanical actions will enable farmers to switch from ordinary tillage to reduced tillage systems: after harvest all residues are removed employing a brush-cleaner and/or an uprooting horizontal blade, together with a broadcast flame treatment to accelerate the dehydration of green residues. Following this soil cleaning phase, the raised beds are prepared for the next cycle using a specifically designed combined-type machine, that integrates a heat treatment apparatus with a vertical axis rotary hoe for shallow tillage. This innovative system prepares the soil between harvests, while ordinary tillage can be applied every third cycle, drastically reducing the intensity of mechanical actions on the soil. In this paper an integrated system, based on the use of the thermal treatment and the minimum tillage is described in detail. Many important farms of the RTE sector have adopted these techniques in their production protocols, proving the effectiveness of integrating the flame treatment, the removal of crop residue, and the minimum tillage for seedbed preparation. An overall agro-ecological equilibrium can be assured, safeguarding soil fertility, reducing or limiting phytosanitary problems and achieving high yield and high quality leafy greens.

\section{EVALUATION OF A RECYCLING TUNNEL SPRAYERS PROTOTYPE FOR VINEYARD TREATMENTS IN SALENTO-APULIA.}

Alexandros Sotirios Anifantis, Biagio Bianchi, Simone Pascuzzi, Francesco Santoro

\section{Department of Agricultural and Environmental Science (DiSAAT), University of Bari Aldo Moro, Bari, Italy \\ E-mail: biagio.bianchi@uniba.it}

Key words: pesticide application, tunnel sprayer, espalier trained vineyard, crop protection.

The recycling tunnel sprayers allow recovering and recycling most of the spray fraction that has not been retained by the canopy, so making efficient pest control possible even at reduced pesticide dose rates. Furthermore, these machines reduce both soil contamination and airborne drift. This thanks to the proximity of the jets to the vegetation and the microenvironment that allows also smaller droplets to reach the target. Within a research program of the Ministry of Education, University and Research and the Ministry of Economic Development, on the European Fund for Apulian Regional Development (PON02 
00657-00186-2866121 Project (EC0_P4)), a trained single-row air-blast tunnel recycling sprayer was developed by an Apulian Company in teamwork with the DISAAT of the University of Bari. This machine was aimed at meeting the requirements of the espaliers trained vineyards located in the Salento (Southern Apulia), where the vegetation is such greatly developed during the final growth stages as significantly reduces the size of the inter-row, so compromising the transit of the machines. The prototype was constituted by a galvanized steel frame on which are located: the fuel tank, the axial fan, the hydraulic system for moving the shields of the tunnel. The recovery system consists of two shields each equipped with a collector at the bottom, where un ejector allows to convey the recovered mixture to the tank.

Simulated treatment tests were carried out in a espalier trained vineyard, located at Cellino San Marco (BR), with the tank filled with a solution of water and a tracer (Tartrazine E-102). The following operating parameters were assumed: volume rate $600 \mathrm{~L} /$ ha and travel velocity of $5 \mathrm{~km} / \mathrm{h}$. After the tests, leaves according to a pre-established pattern were taken from the plants and then analyzed in the laboratory to evaluate the tracer deposit in $\mu \mathrm{L} / \mathrm{cm}^{2}$ of surface area.

The results show that the prototype enables good penetration and a uniform distribution of the spray inside the vegetation, but also presents some problems. Really, starting from the phenological stage of fruit set, when the development of vegetation becomes considerable, the sizes of the machine are unacceptable, because in these conditions a proper homogeneous distribution of the product on vegetation is thwarted and the shields of the tunnel may strip on the vegetation. Therefore, it was necessary to point out technical solutions aimed at to reduce the size of the frame at the front of the machine, where is located the fixed shield. According to these actions, the prototype is more suitable to the characteristics of the studied vineyards and the defined technical solutions can be considered generalizable for the tunnel sprayers employed in such trained vines of the Salento.

\section{PROXIMAL SENSING FOR MULTISPECTRAL ANALYSIS IN VINEYARD}

Pier Riccardo Porceddu, Sara Spitella

Dept. of Civil and Environmental Engineering, University of Perugia, Italy

E-mail: pierriccardo.porceddu@unipg.it

Key words: proximal sensing, vineyard, NDVI.

Always the vineyard is considered homogeneous production unit, which are collected when all the product seems to have uniform characteristics. The necessary corrections to the achievement of the desired objective wine, are performed in the cellar transformation phase. In fact, fixed factors such as soil, exposure and the type of grape and variables, such as the seasons, climate and cultural practices, make the vineyard a set of uneven areas and plants that do not reach the same times the same production goals. It is therefore necessary to adopt appropriate technologies for vineyard monitoring in order to ensure a site-specific management, can detect the state of health, vigor and the physiological needs of plants. In this way it is possible to adapt to the real needs cultivation techniques, for example by agronomic targeted interventions, such as collection scalar, depending on the degree of ripening of the grapes. Through NDVI calculation (Normalized Difference Vegetative Index) you can define the vegetative vigor, directly related to the yield of the crop. Remote sensing is one of the most powerful technologies for the collection of information on growth conditions of different areas of the vineyard. Recently proximal sensing equipments have been developed, capable of interacting with the crop from the ground and at a distance from this even less than one meter. Aim of the research was to assess whether, with these technologies proximal sensing, are detectable areas with different physiological status within the same vineyard, to obtain indications, indirect but reliable, on the state of vegetative development of individual plants, the equilibrium conditions of vegetation and production reached, the potential need for additional agronomic interventions and, finally, the degree of technological ripening of the grapes and, therefore, on different times for its collection. The proximal sensing instrumentation used is the GreenSeeker by Trimble ${ }^{\circledR}$. It is a portable device for spectral reflectance analysis, accompanied by a handheld computer with integrated Bluetooth and high-sensitivity GPS receiver. Captured data is returned in real time, on the handheld display, in the form of a vegetative index NDVI that, with the position of the points measured with GPS, enable the construction of the map of vigor for the same field. After making the choice of the vineyards and their perimeter with the GPS instrument close-scan was performed of all rows (proximal sensing). In order to correlate the measured data with the actual data in the vineyard, have been identified, at random, ten plants, on which the following vegetative parameters: the number of outbreaks, the number of blind buds and of bunches have been detected. For each of these plants were collected, separated and weighed the clusters present. On the musts of these samples were carried out laboratory analysis covering the main indices of maturation: Brix, $\mathrm{pH}$ and total acidity. The measured values, both in the field and in the laboratory, showed interested responses and correlation with data obtained from the proximal sensing.

\section{MECHANICAL HARVEST OF OLIVES USING A TRUNK SHAKER: IDENTIFICATION OF OPTIMAL VIBRATION FREQUENCY, ACCEL- ERATION AND SHAKING TIME.}

Alessandro Leone, ${ }^{1}$ Roberto Romaniello, ${ }^{2}$ Antonia Tamborrino, ${ }^{2}$ Pasquale Catalano, ${ }^{3}$ Giorgio Peri ${ }^{1}$

${ }^{1}$ Department of the Science of Agriculture, Food and Environment, University of Foggia, Foggia; ${ }^{2}$ Department of Agricultural and Environmental Science, University of Bari Aldo Moro, Bari; ${ }^{3}$ Department of Agriculture, Environment and Food, University of Molise, Campobasso, Italy

\section{E-mail roberto.romaniello@unifg.it}

Key words: Olive mechanical harvesting, Orbital shaker, Shaking frequency, Shaking time, Trunk acceleration.

The study concerns on the determination of optimal parameters to use for the mechanical harvesting of olives, using a new trunk shaker on different olive cultivars. The goal of present research is to individuate the optimal values of frequency, duration and acceleration of vibration, to maximizing the removed fruits percentage and to minimizing the loss of vegetable material. The experiments were conducted using a multidirectional trunk shaker. Three 3-D accelerometers were applied to the trunk shaker and on the olive trunk. The research's results shown that the acceleration is linearly correlated with frequency: this linear correlation is acceptable because the low frequency range considered (from 20 to $28 \mathrm{~Hz}$ ), despite the theoretical trend would be described by a second order polynomial. Moreover, the acceleration registered on the trunk decrease of $53 \%$, caused by the rubber pads covering the pliers of the trunk shaker. The optimal frequency determining the maximum percentage of removed fruits were $25 \mathrm{~Hz}$, for Coratina and Ogliarola cultivars. The removed fruit percentage versus time showed a sigmoidal trend. The minimum time to obtain the maximum percentage of removed fruits was $6 \mathrm{~s}$ for both cultivars considered. In conclusion, the research showed the opportunity to optimize the mechanical harvesting of olives, using a multidirectional trunk shaker, opportunely tuning the operative parameters. 


\section{AN ERGONOMIC APPROACH FOR FRONT FOLDABLE ROPS FITTED ON AGRICULTURAL TRACTORS}

Enrico Capacci, Bruno Franceschetti, Valda Rondelli

Department of Agricultural and Food Sciences (DISTAL), University of Bologna, Italy

E-mail:valda.rondelli@unibo.it

Key words: Tractor, Rollover, Foldable ROPS, Manual handling, Grasping area.

Tractor rollover is one of the main causes of fatal accidents in agriculture. Driver's injuries increase considerably if the Roll-Over Protective Structure (ROPS), designed to provide a clearance zone for the driver in the event of tractor rollover, is not correctly fitted on the tractor and used properly during normal field operations. Front-mounted folding ROPSs are widely used on narrow-track tractors because a front foldable ROPS makes the tractor more versatile than a cabin tractor for orchard and vineyard use, allowing it to better adapt to a reduced clearance area in the crop inter-rows. Front ROPS was conceived to be used in the upright position for driver protection in the case of unstable tractor conditions; nonetheless, to use the tractor in narrow spaces the driver is allowed to lower the ROPS only when strictly necessary and in safe conditions with respect to a rollover risk. Folding down the ROPS could be an essential operation for operating in specific conditions such as greenhouses or specially trained vineyards. Lowering and raising the ROPS is a manual operation normally performed by the driver with effects on the working capacity of the tractor since additional time is needed for this. The manual handling of the foldable ROPS, often difficult due to its heavy mass, is considered a potential cause of incorrect ROPS use, being left in the lowered position during the normal tractor operation and consequently with a lack of protection for the driver in the event of rollover. A feasible approach to encourage the correct use of the foldable ROPS is to assist the driver in handling the ROPS, allowing quick folding and raising actions, with efforts suitable for a medium-sized person. A test panel, mainly composed of skilled drivers, was selected to perform an evaluation on five tractors fitted with front foldable ROPS to analyse the ROPS handling with the aim of obtaining feedback allowing the design of foldable ROPSs to be improved in terms of easier, quicker and safer handling.

\section{AMACA: AGRICULTURAL MACHINE COST ANALYSIS APP}

Alessandro Sopegno, Angela Calvo, Remigio Berruto, Patrizia Busato

Università degli Studi di Torino, Dipartimento Scienze Agrarie, Forestali e Alimentari, Grugliasco (TO), Italia

Key words: agricultural machinery costs, agricultural mobile app, agricultural operation cost.

Machinery and equipment are major cost items in farm businesses since many years in different countries. In the last years, moreover, high power machines, new technologies, higher prices for spare parts and energy contributed to the rising of the machines costs. The possibility to know in advance such costs is strategic for the farmers, but the agricultural machine cost determination available by internet applications are lacking of a mobile app. Aim of this work is to fill this gap with an easy to use mobile app, to determine the real machineries costs in different field operations and makes them available via web mobile application using a cross-platform approach. This paper describes the features of the web mobile app AMACA (Agricultural Machine App Cost Analysis) created by the authors using HTML language for the content, JavaScript for the logic part and CSS as a presentation style. To accelerate the development, the jQuery Mobile (JQM), a touch-optimized
JavaScript library, was used. AMACA allows the analysis of traction costs and operation costs. The tool is free, readily available and does not need any installation on the end users devices. The tool was presented at service companies in agriculture, and people liked its features (mobile availability, easy of use, email parameters and results, easy cost calculation).

\section{EVALUATION OF A TOWED OVER-THE-ROW HARVESTER FOR SUPER HIGH-DENSITY OLIVE GROVES}

Alexandros Sotirios Anifantis, Simone Pascuzzi, Francesco Santoro

Department of Agricultural and Environmental Science (DiSAAT), University of Bari Aldo Moro, Bari, Italy

E-mail: simone.pascuzzi@uniba.it

Key words: towed over the row harvester, super high density olive groves, harvesting efficiency.

Actually the fruit farming techniques tend towards the crop intensification, increasing the plant density and reducing the size of the trees. This development is driven by some main factors as the varietal innovation, new types of training systems, the employment of irrigation and especially the mechanical harvesting. The reasons for this general trend of fruit farming systems are based on the labor costs reduction, thanks to the mechanization of cultivation operations joined to the workplaces safety increase. Among the olive field operations the harvesting is the second most expensive of the entire crop cycle, after pruning, so the mechanization of it is critical to the profitability of the olive. In high-density olive groves (super-intensive), the mechanical harvesting continuously with self-propelled straddle machines is carry out, which allow a significant increase in labor productivity amounted to $1800-3000 \mathrm{~kg} / \mathrm{h}$-worker. In fact the entire operation is realized by two workers, one driving the straddle harvester and the other one picking the olives to the harvesting zone, allowing to collect a hectare in 2 hours. Furthermore, the mechanical harvesting continuously in high density olive grove systems allowing to achieve the mains objectives of mechanization: maximum harvesting output; minimal damage to the fruits and vegetation; Minimum total cost. The unit cost of harvesting may reach an incidence of $0.03 €$ per kg of oil extracted, clearly less value even than the cost incidence of mechanical harvesting with trunk shaker with umbrella, considered for the olive intensive cultivation the best management solution. This paper reports the results of tests carried out in a super-intensive olive grove with an innovative harvesting machine manufactured by Pellenc company, CV5045: the harvesting module is not mounted on a self-propelled structure, as with commonly used machines in super-intensive olive groves, but on a special trolley towed. So, this machine requires a tractor of adequate power for its displacement and for the feeding of hydraulic control and electrical devices necessary for the operation (shakers groups, conveyor, proximity probes, etc.). The tests conducted with the tractor NEW HOLLAND T7 210, showed that the harvesting efficiencies is in line with those obtained with the self-propelled straddle, next to $97-98 \%$, then higher than those reported for intensive installations in which the harvest is realized with olive harvester shakers, tree shaker with umbrella (95\%) and single cone (91\%). Moreover, the damage observed on the trees due to the machine harvesting operations, expressed in percentages of broken vegetative axes, were approximately $1.2 \%$, similar to shaker harvester (1.1\%). The self-propelled model, on the other hand, with the driver's cab and the collection module integrated into a single structure allows a high maneuverability of the vehicle during the harvesting operations. The model driven, instead, coupled to tractor and governed by hydraulic devices, that control the alignment with respect to the soil and vegetation, has a less easy maneuverability and requires considerable experience and attention of the tractor driver. 


\section{TECHNOLOGIES FOR REDUCING THE ENVIRONMEN- TAL IMPACT OF AGRICULTURAL AND LIVESTOCK PRODUCTIONS}

\section{ENVIRONMENTAL IMPACT OF ELECTRICITY FROM ANAEROBIC DIGESTION PLANTS: LIGHTS AND SHADOWS}

\section{Jacopo Bacenetti, Marco Fiala}

\section{Department of Agricultural and Environmental Sciences, Production, Landscape, Agroenergy, University of Milan, Italy \\ E-mail:jacopo.bacenetti@unimi.it}

Key words: Life Cycle Assessment, Anaerobic Digestion, environmental sustainability, renewable energy

In the last 20 years, thanks to remarkable public subsidies for the production of electricity from renewable sources, the anaerobic digestion (AD) of agricultural biomass has grown. In 2013, in Italy, according the CRPA, about $7450 \mathrm{GWh}$ of electricity was produced by 1713 agricultural AD plants. Although the agricultural feedstock AD (animal wastes, in particular) has been recognized as an effective solution to reduce greenhouses gases (GHG) emissions, general conclusions about the environmental sustainability of this biomass-to-energy process cannot be drawn. A careful assessment of several environmental concerns must be carried out.

The aim of this study is to evaluate, using Life Cycle Assessment (LCA) approach, the environmental performances of $10 \mathrm{AD}$ agricultural plants. LCA, defined by specific ISO standards, is a holistic method for the assessment of the environmental load related to a production. The 10 AD plants, located in Lombardy and Piedmont regions, are characterized by an electrical power ranging from 100 to $999 \mathrm{~kW}$. Built since 2009 to 2013, they are fed by cereal silages (maize, triticale), animal wastes (pig and cow slurry) and agro-food industry by-products (tomato skins and peels).

The selected functional unit is $1 \mathrm{kWh}$ of produced electricity. The system boundaries involve production, transport and storage at the $\mathrm{AD}$ plant of the feedstock, anaerobic digestion, biogas treatment and conversion by a cogeneration system (CHP, i.c. reciprocating engine). Animal slurries and agro-industry by-products are considered wastes coming from other production processes; therefore, no environmental burden is accounted for their production. For the AD plants fed by animal wastes, considering that the energy generation process substitutes the traditional slurry management in open tanks, environmental credits have been taken into account. Inventory data, collected by mean questionnaires to the plant manager as well as by direct surveys, refers to the period 2012-2014.

Eleven environmental impacts, accounted considering the characterization factors provided by ILCD, were evaluated: climate change (CC), ozone depletion (OD), particulate matter (PM), human toxicity (HT), photochemical ozone formation (POF), terrestrial acidification (TA), terrestrial eutrophication (TE), freshwater eutrophication (FE), marine eutrophication (ME), freshwater ecotoxicity (FEx), and mineral and fossil resource depletion (MFRD).

The results show a huge variability among both the 10 plants and different impact categories. Cereal silage production (when used), methane losses and digestate emissions are the main contributors for the environmental impacts taken into account. Building, maintenance and disposal of digesters and CHP are responsible for a little impact but cannot be neglected in small plants, for HT in particular.

The AD plants fed by slurries and agro-industry residues show a lower impact compared to the ones fed by energy crops For CC, the small power plants, fed with animal slurries and by-products), show negative values (i.e. environment benefits) while the bigger ones, fed mainly by cereal silages, have GHG emissions close to the Italian electric mix. For acidification and eutrophication impact categories, the plants fed with cereal silages present a severe higher impact (2-4 times) respect to Italian electricity mix.

\section{COMPARISON AMONG DIFFERENT TECHNIQUES FOR SLURRY SPREADING: EFFECT ON THE ENVIRONMENTAL PERFORMANCE OF MAIZE CULTIVATION}

Jacopo Bacenetti, Daniela Lovarelli, Marco Fiala

Department of Agricultural and Environmental Sciences, Production, Landscape, Agroenergy, University of Milan, Italy

E-mail: jacopo.bacenetti@unimi.it

Key words: Life cycle assessment, slurry spreading, environmental impact mitigation.

Greenhouse gases emissions from human activities are considered the major causes of global warming. Among the production sectors, agriculture plays an important role on greenhouse gases emissions. Although most of these are due to enteric fermentation, mainly caused by cows, slurry management is also responsible for a considerable environmental impact. In Italy, mainly in Northern Regions, intensive livestock holdings are much developed. Slurry management should aim to the selection of spreading techniques able to reduce ammonia and other nitrogen compounds emissions.

In this paper, the environmental impacts of different pre-sowing fertilisation schemes for the cultivation of a maize hybrid FAO Class 700 have been evaluated using the Life Cycle Assessment (LCA) methodology. The assessed scenarios are:

Scenario A, urea spreading;

Scenario B, superficial slurry spreading and injection after more than 48 hours;

Scenario C, superficial slurry spreading and injection within 2 hours;

Scenario D, direct slurry injection in 7-cm deep furrows.

The selected Functional Unit (FU) is 1 ton of maize silage. The system boundaries include the production of inputs consumed during the life cycle till the farm gate, where silage is stocked in horizontal silos. From the analysis are excluded all processes that consider the silage use. The impact categories evaluated using the ILCD characterisation method are: climate change (CC), ozone depletion (OD), human toxicity (HT), particulate matter (PM), photochemical oxidant formation (POF), terrestrial acidification (TA), freshwater eutrophication (FE), terrestrial eutrophication (TE), marine eutrophication (ME) and mineral, fossil and renewable resources depletion (MFRD).

LCA results obtained from the comparison among the different scenarios are not univocal:

- For CC, scenario A shows the worst environmental performance, followed by scenario D (-11\%) and scenarios B and C (-16\%);

- For OD, scenario A shows again the worst performance followed by scenario D (-33\%) and scenarios B and C (-40\%);

- For HT, scenario A is the worst, whereas the other three scenarios report similar results, with an environmental impact reduction of about $32 \%$;

- For PM, direct soil injection (scenario D) shows the lowest environmental impact, fast injection has similar results (-77\% and $-71 \%$ compared with scenario A, respectively);

- For POF, scenario D is the worst, while mineral fertilisers use (scenario A) has a lower environmental impact;

- For TA and TE, the highest environmental impact is associated with scenario D, while remarkable reductions are associated with sce- 
nario A (-24\%) and mostly with scenarios B and C (-88\% and $-81 \%$, respectively);

- For FE, scenarios B, C and D show similar impacts and scenario A is the best $(-54 \%)$;

- For ME, the lowest environmental impact is associated with scenarios $\mathrm{B}$ and $\mathrm{C}$ and the highest with scenario $\mathrm{D}$;

- For MFRD, scenario A has the highest environmental impact, similarly to B (-3\%), while scenario D shows the best results (-7\%).

\section{PROTOTYPE OF A $\mathrm{CO}_{2}$ FLEXIBLE PLANT FOR COLD STORAGE AND CONDITIONING OF FOOD PRODUCTS}

Biagio Bianchi, ${ }^{1}$ Giuseppe Cavone, ${ }^{2}$ Elsa Carparelli, ${ }^{2}$

Fabrizio Simone, ${ }^{3}$ Pasquale Catalano ${ }^{4}$

${ }^{1}$ Department of Agricultural and Environmental Science (DiSAAT), University of Bari Aldo Moro; ${ }^{2}$ Department of Electrical and Computer Engineering, Polytechnic of Bari; ${ }^{3}$ Department of Mechanics,

Mathematics and Management, Polytechnic of Bari; ${ }^{4}$ Department of Agricultural, Environmental and Food Sciences, University of Molise, Italy

E-mail: biagio.bianchi@uniba.it

Key words: Carbon dioxide, refrigerant, refrigeration plant, food

Recently the European Union has focused its attention on the effect that some emissions from industrial processes on the environment, attempting to reduce, and then eliminate, the use of third-generation refrigerants. Main aim of this paper is to provide a low environmental impact $\mathrm{CO}_{2}$ refrigerant system, to investigate the use of this fluid in food refrigeration and storage applications. The study is part of a wider research program on a pilot plant aimed at testing the use of this fluid with regard to product quality, cost and environmental impact. To this end a network of different sensors was developed: temperature, pressure, $\mathrm{CO}_{2}$ and flow rate, all controlled on LabVIEW platform.

The experimental measurement system was designed to control the key parameters of the prototype system. It is a pilot plant realized in the laboratory and equipped with: a compressor and related gas-cooler, an intermediate heat exchanger and two liquid-gas separators, all of them located outside in an partially covered area near the laboratory, while three cold storage modules ( $1.0 \mathrm{mx} 0.70 \mathrm{mx} 2.0 \mathrm{~m}$ each) were installed in the closed area of the laboratory.

In each module there are: a humidifier, an extractor fan and radiant heating panels on the side walls. Each module is also equipped with a different evaporator: in the cold store 1 a static type evaporator, in the cold store 2 a bi-flow evaporator with suction from the bottom and discharge along the side walls, in the cold store 3 a traditional evaporator with front fan and rear suction. In the laboratory there is also the electrical panel and the control computer.

During the trial, despite the storage conditions and the outside temperature it was often unfavorable compared to those of common industrial $\mathrm{CO}_{2}$ plants, the refrigeration system worked with high efficiency.

The flexibility of the prototype is highlighted by the temperature and relative humidity trends in the cold stores during the experimental tests: it was noted that the thermo-hygrometric regime was very stable in the ventilated storage modules. In fact, the thermal hysteresis is on the order of $\pm 0.5^{\circ} \mathrm{C}$ and, under saturation conditions, excluding the peaks due to the opening of the doors, the hygrometric hysteresis can be considered absent in the cold store 2 and of the order of $\pm 2 \%$ in the cold store 3 . These results also confirm the greater efficiency of ventilation established in the cold store 2, also supported by specific qualitative and microbiological evaluations on the products.

\section{DISTRIBUTION PATTERN OF ORGANO-MINERAL FERTILIZERS IN LOCALIZED APPLICATIONS}

Marcello Biocca, ${ }^{1}$ Roberto Fanigliulo, ${ }^{1}$ Daniele Pochi, ${ }^{1}$ Pietro Gallo, ${ }^{1}$ Giancarlo Imperi, ${ }^{1}$ Daniele Bartolini ${ }^{2}$

${ }^{1}$ CREA-ING Unità di Ricerca per l'Ingegneria Agraria, Consiglio per la ricerca in agricoltura e l'analisi dell'economia agraria; 2SCAM spa

E-mail:marcello.biocca@crea.gov.it

Key words: Fertilization, precision farming, spreaders, seeders, cultivators.

Localized fertilization with granular fertilizers is an agronomic practice of great interest, because it is often associable with other farming operations (eg. planting, weeding, etc.) and because it achieves a greater adherence with the nutritional needs of the crop, thus saving product and causing less pollution. The application quality of the product depends on several factors, which include, on the one hand, the characteristics of the equipment used and the working parameters and, on the other, the physical and mechanical characteristics of distributed fertilizers. For the organo-mineral fertilizers (OMF), which are a rather new group of fertilizers, there is a certain lack of information about the quality of their distribution, although the assessment of the distribution performance of the machines is a prerequisite for the application of precision farming techniques. Therefore, the present work aimed at verifying, for two $\mathrm{OMF}$, the horizontal (i.e. transversely to the forward direction of the machine) and the longitudinal (i.e. parallel) uniformity of distribution, expressed in terms of coefficient of variation (CV). Granular urea was used as reference fertilizer, to compare the studied $\mathrm{OMF}$ with a widely employed and efficient fertilizer in terms of distribution ease. Firstly, all fertilizers were investigated for their main physical characteristics. The OMF showed: a bulk density varying from 830 and $990 \mathrm{~kg} \mathrm{~m}^{-3}$; a particle size distribution with a median diameter from 1.0 to $1.3 \mathrm{~mm}$; a relative humidity from 1.5 to $1.8 \%$. The tests were carried out with the following three machines: a pneumatic precision seed drill; a cultivator-fertilizer spreader; a fertilizer spreader for orchards and vineyards. Depending on the machinery, static or dynamic tests of distribution were carried out. The data obtained in the tests underwent to an ANOVA statistical test to individuate significative differences among treatments. Preliminary results show that the average CV measured both on horizontal and on longitudinal distribution with the three fertilizers, were similar. OMF showed a slightly better performance (i.e. more uniformity) with respect of urea. In conclusion, results indicate that the studied fertilizers are suitable for localized fertilization. In the future, we plan to expand the survey to other formulated fertilizers and fertilizer spreader machines.

\section{ENVIRONMENTAL ANALYSIS OF PRODUCTIVE CHAIN OF AN OLEAGINOUS CAMELINA (CAMELINA SATIVA) FOR THE PRODUCTION OF BIO PRODUCTS}

Lenin Javier Ramirez Cando, ${ }^{1,4}$ Antonio Guiso, ${ }^{1}$ Paolo Spugnoli, ${ }^{1}$ Luciana G. Angelini, ${ }^{2}$ Silvia Tavarini, ${ }^{2}$ Roberto Matteo, ${ }^{3}$ Luca Lazzeri ${ }^{3}$

${ }^{1}$ Dipartimento de Gestione di Gestione Sostenibile dei Sistemi Agrari, Alimentari e Forestale (GESAAF), Universitá degli Studi di Firenze; ${ }^{2}$ Dipartimento di Scienze Agrarie, Alimentari e Agro-ambientaliUniversitá Degli Studi di Pisa, Pisa; ${ }^{3}$ Consiglio per la ricerca in agricoltura e l'analisi dell'economia agraria, Centro di ricerca per le colture industriali (CRA-CIN), Bologna, Italia; ${ }^{4}$ Grupo de investigación en Ciencias Ambientales (GRICAM), Universidad Politécnica Salesiana, Quito, Ecuador

E-mail:ramirez@ups.edu.e

Keywords: Camelina; LCA; Bioproducts

The growing demand of raw materials for the bio-refineries and the 
increase in bio-products demand could be considered important opportunities for Italian agriculture. Among the innovations, it is expected the introduction of new non-food crops resulting in an increase in biodiversity as well as an environmental impact reduction achieved by replacing conventional refinery products (hydrocarbons) with products derived from bio-refineries. Additional benefits to the economic and environmental sustainability of the supply chain can be derived from the use of by-products generated in the chain of bio-refinery, not only for the production of renewable energy, but more generally in Green Chemistry, increasing its economic value. The present work analyzes the life cycle (LCA) of products and by-products from processing of seeds and crop residues of Camelina (Camelina sativa). The aim is to evaluate the environmental impact due to the production chain of bioproducts with different functionalities (energy, cosmetics, fertilizers, lubricants, feed, etc.). The indicator chose is the Global Warming Potential (GWP) of the functional unit (1 MJ of Jet Fuel) and its associated by-products. The impacts of the farming were determined with agronomic and qualitative data obtained as part of the SUSCACE project activities on the cultivation of Camelina in two areas (Pisa and Bologna). These can be considered as typical chemical-physical characteristics of soil and climatic conditions of central Italy. As source of secondary data was used the ecoinvent database, while the impact assessment of the downstream sector from farming to pressure extraction was performed, according to IPCC, using Simapro software taking into account the transformation processes implemented for the exploitation of by-products obtained along the entire production chain as well as transportation. The results of the LCA of considered chains were compared with those of comparable conventional products, that is: products of inorganic origin, and derived from the cultivation of other competitive species according to RED (DIRECTIVE 2009/28/CE). Regarding the cultivation phase of Camelina, the impact related to the functional unit in Bologna is found to be on average $28 \%$ higher than that in Pisa, as consequence of a greater diesel requirement (30\% lower in Pisa), and its lower yield (41\% higher in Pisa). However, it is relevant to show that $\mathrm{N}$ requirements of Bologna were considerably lower than Pisa. Consequently, $\mathrm{N}_{2} \mathrm{O}$ emissions are lower with significant repercussions on the impact of the final product and each production step. Regarding the end life scenario the advantage of bio-products derives from their biodegradability that substantially reduces or eliminates the disposal processes and their lower toxicity when it is compared to fossil-based product.

\section{CONTROLLED MECHANICAL VENTILATION TO REDUCE PRIMARY ENERGY CONSUMPTION IN AIR CONDITIONING OF GREENHOUSES}

Claudio Perone, Flavio Fucci, Pasquale Catalano, Giovanna La Fianza, Ferruccio Giametta, Lucio Brunetti

Department of Agricultural, Environmental and Food Sciences, University of Molise, Italy

E-mail: claudioperone@gmail.com

\section{Keywords: Mechanical ventilation, Greenhouses, Heat recovery}

The increase of annual crop yield in greenhouses is possible only through a very close control of the internal conditions. Currently available conditioning plant solutions require high investment costs. In addition, also high operational costs are required for an efficient solution without reducing yield crop or quality. Therefore, the conditioning of the internal air of a greenhouse occurs through the use of fossil fuels, especially during winter. Ventilation systems could allow proper control of temperature, relative humidity and $\mathrm{C} 02$ rate. For this purpose a research is being carried out. A prototype of a mechanical ventilation unit and two climate chambers for the reproduction of external and internal air was built in laboratory. The recovery unit is equipped with a heat pump and is able to increase the thermal energy recovered, by the flow of exhaust air, through a high efficiency heat exchanger. A first study was carried on to evaluate the energy performances of the system during the control of temperature in winter season. Tests were performed at different temperature values of simulated external air $\mathrm{T}_{\mathrm{E}}$ $\left(-5^{\circ} \mathrm{C}, 0^{\circ} \mathrm{C}, 5^{\circ} \mathrm{C}\right.$ and $\left.10^{\circ} \mathrm{C}\right)$ and a fixed (reference) internal simulated greenhouse temperature $\left(20^{\circ} \mathrm{C}\right)$. Each trial was performed with a ventilation flow rate of $535 \mathrm{~m} 3 / \mathrm{h}$. The resulting coefficient of performance of the overall system (COPs) is 9.50 at $0^{\circ} \mathrm{C}, 8.86$ at $5^{\circ} \mathrm{C}$ and 6.62 at $10^{\circ} \mathrm{C}$ respectively. It has to be highlighted that during the trials conducted at $-5^{\circ} \mathrm{C}$ the compressor behaved as an on-off type. This is due to a safety mechanism for the defrost of the evaporator. Also the ventilation flow rate was reduced to avoid a too low value of the supply in air temperature. For the other trials $\left(\mathrm{T}_{\mathrm{E}}=0^{\circ} \mathrm{C}\right.$ or $\left.5^{\circ} \mathrm{C}\right)$, the overall COPs decreases when the external temperature increases, due to a lower difference between external and indoor air enthalpy. Ultimately it can be concluded that exist an upper and a lower limit value of external temperature to which it is appropriate to change the operating setting. For values lower than the lower limit it is possible to operate with the only passive recovery and a heating system at service of greenhouse; while, for temperature values higher than the upper limit it is possible to operate with the only active recovery, until the external conditions will allow freecooling/freeheating.

\section{ACIDIFICATION OF RAW AND DIGESTED SEPARATED SOLID FRACTIONS: EFFECTS ON AMMONIA EMISSION DURING STORAGE}

Fabrizio Gioelli, Elio Dinuccio, Dalibor Cuk, Luca Rollè, Paolo Balsari

Università di Torino, Dipartimento di Scienze Agrarie Forestali e

Alimentari (DISAFA), Grugliasco (TO), Italia

E-mail: fabrizio.gioelli@unito.it

Key words: Animal wastes, ammonia, acidification, sulfur, separated solid fraction.

The revision of the 2001/81/CE National Emission Ceiling Directive (NECD) has set new targets for the reduction of gaseous pollutants $\left(\mathrm{SO}_{2}, \mathrm{NOx}\right.$, ammonia) released to the atmosphere in the European Union. The target for Italy sets a $5 \%$ reduction of ammonia $\left(\mathrm{NH}_{3}\right)$ emission by 2020 with respect to the 2005 baseline. A further $9 \%$ reduction by 2030 is currently under negotiation, but it's likely to be confirmed. In Italy the livestock sector is responsible of about $77 \%$ of total $\mathrm{NH}_{3}$ emissions (ISPRA, 2015). Besides $\mathrm{NH}_{3}$, manure handling in Italy contributes to $13 \%$ of $\mathrm{N}_{2} \mathrm{O}$ and to $8 \%$ of methane $\left(\mathrm{CH}_{4}\right)$ losses. According to this figure, measures to abate emission of pollutants from the national territory have to be strongly focused on the livestock sector. A way to abate emissions from slurry (with special regards to ammonia) is to reduce its $\mathrm{pH}$ below 6.0 so that the nitrogen is kept in the ammonium form. The technique is widely used in Denmark where concentrated acids (namely sulfuric) are commonly used. Nevertheless, some limitations to their use, such as their hazards to human health, are important issues that need to be overcome. Furthermore at present, the acidification of solid manures (e.g. farmyard manure and slurry separated solid fraction) is not possible due to a lack in technology and alternative additives to sulfuric acid.

To cover this gap in knowledge, the DiSAFA Waste Management Group carried out a laboratory-scale preliminary study to assess the feasibility to acidify digested and undigested separated solid fractions by using a commercial powdery sulfur-based additive. Pig slurry and digestate were mechanical separated by using a lab-scale screw-press device. After separation, sulfur was added to the separated solid fractions at three rates: $0,5 \%, 1,0 \%$ and $2 \%$ (weight/weight). Ammonia loss- 
es were afterwards measured along the storage phase of both sulfuramended raw solid fractions (trial 1) and digested solid fractions (trial 2). Unacidified samples of both the fractions were used as control. $\mathrm{pHs}$ and ammonia emission patterns were recorded along 60 days (in trial 1) and 30 days (in trial 2). Results showed that the sulfur amendment is able to abate the solid fractions' pHs. A significant decrease of ammonia losses (regardless to the sulfur application rate and separated solid fraction type) was observed. At the highest sulfur application rate $(2 \% \mathrm{w} / \mathrm{w})$ a reduction of up to $70 \%$ of ammonia losses was measured from raw separated solid fraction when compared to the control. Similar results were achieved from the digested solid fraction, with emission reduction of up to $67 \%$.

Further trials are in progress to evaluate the possibility to acidify the slurry by powdery sulfur prior to mechanical separation in order to abate emission from both the obtained solid and liquid fractions.

\section{DRIFT EVALUATION TOOL: A SOFTWARE TO ADDRESS FARMERS IN THE SELECTION OF SPRAY DRIFT MITIGATION MEASURES}

Paolo Marucco, Paolo Balsari

\section{Dipartimento di Scienze Agrarie Forestali e Alimentari Università di} Torino, Italia

E-mail:paolo.marucco@unito.it

Key words: drift, mitigation, sprayer, training.

To comply with the contents of the European Directive on sustainable use of pesticides related to spray drift reduction, different mitigation measures (either direct or indirect) can be adopted; these latter were inserted in the Best Management Practices to prevent spray drift that were defined in the ambit of TOPPS-Prowadis project (www.toppslife.org e www.topps.unito.it).

In order to allow farmers and advisors to evaluate the actual drift risk in the specific agricultural and environmental context in which they are going to operate the spray application and therefore to support them in the selection of the sprayer operating parameters and of the devices more suitable to contain this risk, a specific "Drift Evaluation Tool" software was developed, always in the ambit of TOPPS-Prowadis project.

The software is available in different languages and has three versions: one for field crop sprayers, one for orchard sprayers and one for vineyard sprayers. The user is guided through a short questionnaire with multiple answers that, in its first part, enables to get an indication of the drift risk on the basis of the environmental conditions (air temperature and humidity, wind speed and direction) and of the field conditions (crop growth stage, features of the area adjacent to the sprayed field, etc.) in which the farmer is operating. On the basis of these information the software calculates an index value of drift risk and elaborates a correspondent message with the indications of the drift mitigation measures needed.

The second part of the software is focused on the sprayer technical features and operating parameters that are used by the farmer. The user, always through a set of questions with multiple answers, can insert the data related to his own sprayer in terms of spray drift reducing techniques present on the equipment (e.g. air induction nozzles, air sleeve, etc.) and operating parameters (e.g. forward speed, boom height, etc.).

The software now verifies if the sprayer setting adopted by the farmer can face the potential drift risk assessed in the first part of the questionnaire and provides a graphical representation of the potential and of the real drift index values with coloured bars. It is possible to save all the information inserted by the user and the corresponding results elaborated by the software with the relative recommendations on how to operate properly, so that the user can store them and, if necessary, show them to the competent Authorities.

This tool is free and can be used at www.topps-drift.org also for training farmers as recommended by the EU Directive on sustainable use of pesticides. It is useful to help farmers and advisors to know the drift risk in the moment they are going to apply pesticides and to address them to adopt devices and good practices enabling to contain spray drift and the related negative effects on the environment.

\section{STUDY OF THE EFFECT OF A NEW ADJUVANT ON SPRAY DRIFT MEASURED IN VINEYARD}

Paolo Marucco, Paolo Balsari

\section{Dipartimento di Scienze Agrarie Forestali e Alimentari Università di} Torino, Italia

\section{E-mail:paolo.marucco@unito.it}

Keywords: drift, adjuvant, droplet size.

Buffer zones are the most common risk mitigation measure enforced in European Member States in order to meet the protection goals for pesticides in surface water, laid down in Regulation (EC) $1107 / 2009$.

The use of adjuvants to prevent spray drift is a widespread practice in Northern America and is now becoming more and more popular also in Europe, as a way to reduce these buffer zones to more manageable widths (EU Directive 128/2009 on the sustainable use of pesticides). A new adjuvant (GF 3380) was developed by Dow AgroSciences which aims at reducing spray drift by acting on the droplet size in spraying solutions. The adjuvant was tested in the laboratory and in field conditions, in combination with a Spinetoram ${ }^{\circledR}$ insecticide, to assess its effect on the droplets size and on spray drift when used alone or in combination with hydraulic nozzles. In the laboratory we used a laser diffraction instrument Malvern Spraytec to compare the droplets size pattern generated by the following spraying solutions: $a$ ) pure water; $b$ ) water + Spinetoram ${ }^{\circledR}$ insecticide; c) water + GF-3380 adjuvant; d) water + GF 3380 adjuvant + Spinetoram ${ }^{\circledR}$ insecticide, each of them sprayed using conventional and air-induction nozzles.

Additional tests were carried out in a small wind tunnel with the aim to assess the distortion of the spray pattern from a single hollow cone nozzle (either conventional or air induction type) when fed with pure water or with a solution of water + adjuvant GF 3380, in presence of an air velocity ranging between 1.7 and $2.8 \mathrm{~m} / \mathrm{s}$.

The field trials were carried out in a Muller Thurgau vineyard trained at "Pergola semplice" system, using a conventional axial fan sprayer equipped with conventional and with air-induction hollow cone nozzles operated at 9 bar pressure, adjusted to apply a spray volume of about $750 \mathrm{l} / \mathrm{ha}$. The trial was performed according to the ISO 22866 test methodology, placing arrays of samplers downwind the sprayed vineyard at defined distances between 3 and 25 meters from the outer vine row and spraying either a water solution of yellow Tartrazine E102 tracer or spray mixtures containing only the Spinetoram ${ }^{\circledR}$ insecticide and the Spinetoram® insecticide plus the adjuvant GF 3380.

The results showed that the adjuvant enabled an increment of the Volume Median Diameter (VMD) especially on conventional nozzles (from 90 to $109 \mu \mathrm{m}$ ) and a reduction of the amount of very fine droplets $(<100 \mu \mathrm{m})$, which are more prone to drift. This lead to positive effect in terms of drift reduction in comparison to the application either of pure water or of the conventional spray mixture as revealed by the results obtained in laboratory in the wind tunnel and in the field. In this latter case the application of the adjuvant combined with the use of air induction nozzles allowed to contain spray drift by $85 \%$ with respect to the reference application setting (use of conventional nozzles spraying the conventional spray mixture). 


\section{PRECISION AND DIGITAL AGRICULTURE: THE ITALIAN PANORAMA}

Michele Pisante, ${ }^{1}$ Federico Pallottino, ${ }^{2}$ Corrado Costa, ${ }^{2}$ Francesca Antonucci, ${ }^{2}$ Marcello Biocca, ${ }^{2}$ Carlo Bisaglia, ${ }^{2}$ Paolo Menesatti

${ }^{1}$ Consiglio per la ricerca in agricoltura e l'analisi dell'economia agraria (CREA); ${ }^{2}$ Consiglio per la ricerca in agricoltura e l'analisi dell'economia agraria (CREA), Unità di ricerca per l'ingegneria agraria (ING)

\section{E-mal:michele.pisante@crea.gov.it}

Key words: Precision agriculture, digital agriculture, keyword analysis.

The reduced resources availability and the need to increase productivity, in relation to the work required, have given a strong incentive to the development and adoption of techniques to streamline operations and make more sustainable the agricultural and forestry sectors. The Precision Agriculture (PA) is based on management methods based on observation, and the response to the variations that exist within specific areas (e.g. soil, moisture, organic matter, etc.), and actions targeted to optimize the operations leading to an advanced sustainability. The PA development has been made possible, since the early 90 s, thanks to the availability of an articulated technological structure mainly represented by the growing geographical positioning systems (GPS, GLONASS, GSNN), geographic information systems (GIS) and many applications (sensors, actuators, control of sections, guidance systems, etc.). Italy has a fragmented reality, with an extremely rich and diverse territory.

Through an action promoted by the Ministry of Agriculture and Forestry (Mipaaf) it was carried out a survey regarding the PA applications and research within the Italian scientific panorama. This was done in order to highlight future technical and economic development prospects in relation to research projects and technology transfer concluded, committed execution, start-ups and adoption, at operational level, of their systems and methodologies.

The purpose of this work was to analyze the results identifying weaknesses and strengths as well as to provide a useful tool for structuring a medium to long-term action. The information required in the survey concerned the duration and size of the research activities, the objective, material and methods, main results and the actions taken for their dissemination / technology transfer. In addition, the survey included the demand for infrastructure and technological needs.

The survey, which has been open from November 2015 to February 2016, has gathered 172 contributions among which projects, research topics and business cases. Out of these, 140 records have fallen in issues properly belonging to the PA domain, while other 32 projects have proven to regard specifically environmental problems and therefore subject to be processed separately. In order to identify the most common research themes, it was performed an analysis regarding the frequency of the keywords entered by the participants. Considering 313 keywords entered were identified 24 main topics representing the PA research landscape. The most frequent appeared to be the researches on sensors, mapping and crops protection from insects, fungi and weeds. Regarding instead the specific production chains, the most frequent has been the viticulture, followed at a distance from the cereal, olive, rice farming, forestry, animal husbandry, grassland and fruit. It were shown 31 keywords with a minimum frequency of 3 . It can be seen that, apart from the obvious inclusion of the keyword "precision agriculture", the most common were "UAV" (Unmanned Aerial Vehicle) and "precision viticulture".

\section{AUTOMATIC CONTROL OF AXES GEOMETRY ON A DISC HARROW}

Pier Riccardo Porceddu, Sara Spitella

Department of Civil and Environmental Engineering, University of Perugia, Italy

E-mail: pierriccardo.porceddu@unipg.it

Key words: disc harrow, geometry automatic adjustments

In agriculture it is increasingly necessary to reduce production costs, to safeguard the environment and provide quality products. These goals can be achieved through the multiple technologies available today. In particular it is possible to provide the right input to the ground and to the crop, according to their actual needs, which may be different within the same plot. Even the cultivation machines can operate in a different manner, by suitably adjusting their organs according to the requirements of the ground. The disc harrow is a machine utilized for crushing and homogenization of soil. It has a large number of smooth concave discs, arranged on two or four axes, working in a mirror manner.

This research modified a disc harrow in order to automate its adjustments, so that it takes the best geometry in regard to the soil type. Early tests were done on different soil type. 


\section{MODELING AND AUTOMATION FOR PROCESS PRECISION MANAGEMENT}

\section{TESTING OF A SIMPLIFIED OPTICAL SYSTEM FOR RAPID RIPENESS EVALUATION OF WHITE GRAPE (VITIS VINIFERA L.) FOR FRANCIACORTA SPARKLING WINE}

Roberto Beghi, Valentina Giovenzana, Raffaele Civelli, Roberto Oberti, Riccardo Guidetti

\section{Department of Agricultural and Environmental Sciences (DiSAA), Università degli Studi di Milano, Italy \\ E-mail: roberto.beghi@unimi.it}

Key words: non-destructive analysis, vis/NIR spectroscopy, white grape, ripening, chemometrics

Establishing ripeness at harvest is a crucial issue since fruit quality is closely related to it. The search for non-destructive methods which could explore a large number of samples and give a rapid and comprehensive overview of ripening would be helpful. The aim of the research was to design, build and test a prototype of a low-cost and user-friendly device to support small-scale growers in determining the optimal harvest date according to grape ripening degree.

The acquisition of the spectral reflectance at four specific wavelengths $(630,690,750$ and $850 \mathrm{~nm})$ was proposed. Nevertheless, attention was given to the modularity and versatility of the system.

Light emitting diode (LED) technology was chosen as the light source, to achieve the capability to individually adjust the light emission intensity for each measurement channel. A customized optical fiber was specifically designed for the application in order to optimize the radiation transmission.

The prototype was tested for a rapid estimation of ripening parameters of grape for Franciacorta wine directly in field. At the same time, spectral measurements on grape berries were performed (for data comparison) with a commercial portable vis/NIR spectrophotometer operating in the wavelength range of 400-1000 nm, directly in the field too.

A total of 95 bunches of white grapes were collected and nondestructive analyses were carried out on each sample using both the LED based system and the commercial vis/NIR spectrophotometer.

The correlation between the spectral data matrix from the commercial device and the reference parameters (SSC and TA) were carried out.

Finally, a classification analysis was performed.

The percentages of correctly and misclassified grape samples were determined according to ripeness thresholds for the analyzed parameters (ripe $>17^{\circ}$ Brix for SSC and $<7 \mathrm{~g} \mathrm{dm}-3$ for TA) suggested by the Franciacorta Consortium.

Overall PPV results deriving from the simplified system showed a slightly low classification capabilities (SSC on berry $=79.0 \%$, SSC on bunch $=77.5 \%, \mathrm{TA}=84.3 \%$ ) compared to the commercial device (SSC on berry $=84.6 \%, \mathrm{SSC}$ on bunch $=89.5 \%, \mathrm{TA}=90.5 \%$ ).

This means that only a small loss of information was noticeable between the PLS models calculated using 2048 wavelengths and the MLR models calculated employing only the four channels of the simplified device, especially for the TA estimation. Classification performances related to the two optical instrumentations reflect the trend of the quantitative PLS and MLR models confirming the small loss of information using only four wavelengths and, consequently, the applicability of the simplified LED system.

\section{PRECISION LIVESTOCK FARMING: PROTOTYPING SENSOR-BASED APPLICATIONS}

Giovanni Chessa, Giuseppe Todde, Maria Caria, Lelia Murgia, Filippo Gambella, Antonio Pazzona

\section{Dipartimento di Agraria, Università degli Studi di Sassari, Italia}

E-mail: giovachessa@uniss.it

Key words: animal welfare, Arduino, hardware, software, Bluetooth

In livestock production, the monitoring and control of farm environment and animal biological parameters, represent the fundamental part of Precision livestock farming (PLF) techniques. The primary goal of PLF is to develop a farm management system based on the real-time monitoring of these variables. A PLF system is formed by three parts: a physical part, named hardware, which include sensors, actuators and microcontrollers; a part for processing and presentation of data known as software; a part for the communication, called network for transmitting and receiving the information. Mathematical models for data processing and Graphical User Interface (GUI) are included in the software loaded into the microcontroller. The recent miniaturization and reduction of production costs of new technologies can provide researchers with innovative tools to overcome the main constraints of the commercial systems provided for the livestock sector, which are the hardware modularity and its closed source software (commercial software or licensed). Many of current's systems present on the market, in fact, allow to add additional sensors and actuators to the system only if they belong to the same trademark, and also the manufacturers often do not offer a complete assortment of sensors for all the measurable parameters in animal farms.

The aim of the study was to develop two systems using some open source sensors, actuators and micro-controller. The first one is a system for monitoring the rectal temperature of the animals, which is able to send data via Bluetooth to a smart phone. The micro-controller used was an ATmega32U4 (Arduino Pro Micro-5V/16MHz), characterized by: low power consumption, a high performance 8 bit CMOS and low cost. The temperature was read using the LM35 analogic sensor, which can measure in a range from $-55^{\circ} \mathrm{C}$ to $150^{\circ} \mathrm{C}$. A Class 1 Bluetooth serial module, which has range of about 100 meter, was connected to Arduino creating a wireless serial link between an Android phone and the Arduino board. The application for receiving data on an android smart phone was created using App Inventor that is an innovative Android application creation software developed by Massachusetts Institute of Technology (MIT). This app is free available on Google Play Store under the name animal_temp.

The second system is a prototype for air quality stable monitoring, which is able to detect parameters, such as Particulate Matter, $\mathrm{CO}, \mathrm{CO}_{2}$, $\mathrm{NO}_{2}, \mathrm{O}_{3}, \mathrm{CH}_{4}, \mathrm{H}_{2} \mathrm{~S}, \mathrm{NH}_{3}$. The system used a Waspmote which is an open source wireless sensor platform focused on the implementation of low consumption modes to allow the sensor nodes to be completely autonomous and battery powered. The air quality parameters were collected using the Waspmote Gases PRO Sensor Board. The board consists of a robust waterproof enclosure with specific external sockets to connect a sensors, a solar panel for alimentation, an antenna for data transmission and a USB cable in order to reprogram the node. 


\section{CONSERVATIVE PRECISION AGRICULTURE: FIRST ECONOMIC AND ENERGETIC ASSESSMENTS WITHIN THE AGRICARE PROJECT}

Donato Cillis, Andrea Pezzuolo, Francesco Marinello, Luigi Sartori

Department of Land, Environment, Agriculture, and Forestry University of Padova, Italy

E-mail:donato.cillis@studenti.unipd.it

Key words: Precision Agriculture, Conservation Agriculture, Economic balance, Energetic analysis.

The integration of conservation tillage techniques with the principles of site-specific management characterising precision agriculture is an innovative feature aimed to achieve better economic and environmental sustainability, increasingly required by Community agricultural policies.

In fact, the most efficiency use of inputs, one of the benefits related to precision agriculture technology, could mitigate the problem linked to the conservation tillage techniques on some crops in terms of yield, which would put in secondary place the countless agronomic and environmental advantages deriving from them. Therefore, quantify the economic and energetic potential benefits obtainable from possible synergies allows to collect useful information for adapting conservation tillage techniques to the spatial and temporal variability characterising the fields. The experimentation, got to its second year of activity, is performing under the LIFE + AGRICARE project (LIFE13 ENV IT AGRICARE 0583) at the pilot and demonstrative farm Vallevecchia of Veneto Agriculture, compares three conservation soil tillage techniques (minimum tillage, strip tillage and no tillage) with conventional tillage techniques, examining four different crops in a specific rotation (wheat, canola, corn, soybean).

According to the different homogeneous zones derived from the study of the variability, the different conservation tillage techniques managed with variable rate treatments are compared with a central plot characterized by fixed-rate application of inputs that acts as a test. From the study of the variability can be observed that the study area is composed by 4 homogeneous zones with different production potential. On the basis of their features, the optimal rates of nitrogen fertilizer and seed applicable to each crops and soil tillage technique have been identified by consulting the elaboration derived from the predictive model SALUS. Thanks to the portion of the field managed in a fixed rate used as a test, it is possible to observe the contribution made by precision farming and the possible synergies established with the different conservation tillage techniques.

The yield data relating to the yield maps coming from the first year of the experimentation were compared and calibrated in order to have the realistic production data of each homogeneous zone; with these data, it has been performed an economic and energetic analysis that has allowed to quantify the gross income and the net energy for different homogeneous zones characterising the study area.

The preliminary results show that all the conservation soil tillage techniques achieve a positive synergy by adopting the principles and the technologies of precision agriculture. The automatic guidance system and the devices adopted, capable of performing the variable rate application of inputs such as seed and fertilizer, have allowed to increase the efficiency of use of inputs enjoying better economic and energetic results than the test managed with a fixed rate application of input.

Finally, starting from the yield maps have been made economic and energetic maps showing the points of the field characterised by drop or gain in terms of gross income, and high or low net energy profits for each thesis.

\section{DEVELOPMENT AND PRELIMINARY TEST OF A MOBILE LAB FOR THE ORCHARD CROP MONITORING}

Daniela D'Auria, Gianluca Ristorto, Fabrizio Mazzetto

Libera Università di Bolzano, Facoltà di Scienze e Tecnologie, Italia

E-mail:daniela.dauria@unibz.it

Key words: NDVI, Lidar Sensors, Optical Sensors, Precision Agriculture.

The automated crop monitoring is currently still a challenge aimed at both consolidating the ICT in the agricultural industry and implementing a new concept of information system for the agri-environmental company. Moreover, this kind of monitoring is an essential point for the precision agricultural application, especially for the intervention of farming therapy (such as fertilization, treatment, thinning) where the knowledge of the farming physiological state becomes essential for the automatic control of the process.

Thus, crop monitoring is becoming more and more relevant for both the information management applications and for the automation of the field methods. These applications significantly affect the type of carrier (airplane, drone, tractor, even if a fixed station) to be equipped with sensors (optical, ultrasound etc.) suited for real measurements.

In fact, the classical approaches of remote sensing return top-viewbased recoinnaissance and generate thematic maps, from which then obtaining illustrated maps used for the automation of the delayed processes. Differently, the ground sensing survey (or proximal sensing), typically used in orchard, exploits some sensors - mounted on a mobile ground carrier - returning some three-dimensional maps according to the side-view logic.This latter approach, is currently the most used for real-time automation intervention and is preparatory for robotic applications.

Furthermore, in the context of a project for crop monitoring (Monalisa Project), a mobile Lab has been developed in order to implement crop monitoring in orchard based on a combined use of Lidar (stereoscopic configuration) and optical sensors (NDVI).

An inference algorithm combine the data related both to the canopy volume and to the physiological state (acquired from the NDVI index), thus identifying different types of stress situations.

In this study, we present the preliminary diagnosis algorithm used to determine the phytosanitary status of the plants; then some results obtained from the measurements in a controlled environment are shown.

Future work will be devoted to the design, the development and the use of a specific index in order to improve the efficiency of the overall process and to be applied for the next experiments. 


\section{COMPARATIVE STUDY ON THE USE OF A NON-DESTRUCTIVE OPTICAL SENSOR (MULTIPLEX3 ${ }^{\circledR}$ ) FOR THE MONITORING OF THE ANTHOCYANINS CONTENT IN RED BERRY FRUITS}

Antonio Dore, ${ }^{1}$ Maria Giovanna Molinu, ${ }^{1}$ Antonello Petretto, ${ }^{1}$ Luisella Sistu, ${ }^{2}$ Davide Piccirilli, ${ }^{2}$ Viviana Guido ${ }^{2}$ Giuseppe Todde, ${ }^{2}$ Antonio Pazzona, ${ }^{2}$ Filippo Gambella ${ }^{2}$

${ }^{1}$ Consiglio Nazionale delle Ricerche, Istituto di Scienze delle Produzioni Alimentari, U.O.S. Sassari; ${ }^{2}$ Università degli Studi di Sassari, Dipartimento di Agraria, ezione Ingegneria del Territorio, Sassari, Italia

\section{E-mail antonio.dore@ispa.cnr.it}

Key words: anthocyanin content, Multiplex $3^{\circledR}$, red berry fruits, proximal sensing.

The preliminary results of a comparative study on the determination of the anthocyanins content in red berry fruits by a portable fluorescence-based optical sensor (Multiplex $3^{\circledR}$ ) are reported. Commercially available Multiplex $3^{\circledR}$ was used to measure the "Fluorescence Excitation Ratio Anthocyanin Relative Index" (FERARI index) in red plums (Prunus domestica, L., cv Nero Sardo, Dore A., Stanley) and red grapes (Vitis vinifera, L., $c v$ Monica and Cagnulari). In both species the FERARI index was related to the total anthocyanins content, such variable was determined by UV-Vis spectrophotometry and was expressed as $\mathrm{mg} / 100 \mathrm{~g}$ of peel of malvidin 3 -glucoside, and as $\mathrm{mg} / 100 \mathrm{~g}$ of peel of cyanidin 3-glucoside, for grapes and plums, respectively. A good correlation between fluorescence index and peel anthocyanins content in all the plum cultivars was observed. On the contrary, only for one grape cultivar (Cagnulari) was found a correlation. Moreover, FERARI index and anthocyanins content showed a linear relationship in plums, whereas it was logarithmic in grapes. Finally, the Multiplex $3{ }^{\circledR}$ allowed to detect a larger range of anthocyanins content in plums than in grape. Preliminary results showed that the fluorimetric-based optical sensor Multiplex $3{ }^{\circledR}$ can be an effective tool for monitoring anthocyanins content in the peel of red plums. Moreover, a marked difference in its use depending on the species observed.

\section{ENERGY CHARACTERISTICS ASSESSMENT OF RESIDUES BY MEANS OF INFRARED SPECTROSCOPY}

Manuela Mancini, Andrea Pizzi, Chiara Mengarelli, Giorgio Rossini, Ester Foppa Pedretti, Giuseppe Toscano, Andrea Renzi, Daniele Duca*

Università Politecnica delle Marche - Agricultural, Food and

Environmental Science, Ancona, Italy

E-mail: d.duca.univpm.it

Key words: olive pomace, PLS, PCA, olive oil, infrared spectroscopy.

In the last few years, the use of biomass for energy use is becoming increasingly important both for its renewable nature and for its low cost in comparison to fossil fuels. In particular, the residuals of the agricultural sector assume high interest for their high availability, low cost and wide margin of development. Furthermore, the use of these biomass has different advantages in terms of sustainability compared to dedicated biomass.

Considering the high olive oil production in the Mediterranean countries, it is very interesting the pomace, a by-product of olive oil production chain. However, some critical issues related to this biomass are to be taken into account, i.e. the production seasonality and the high variability of its characteristics. As a consequence, a characterization of the main physical-chemical parameters associated to the solid biofuel quality is necessary.

The infrared spectroscopy (IRS) is a rapid and low-cost technique that allows to provide information on the biomass quality and presents several advantages compared to the standard laboratory analysis.

The development of an analytical tool based on infrared technique could be particularly useful for the operators of the sector since it allows to assess the pomace biomass quality quickly and without the use of specialized operators.

In particular, in this study, samples from different olive oil mills of the Marche region are collected and subsequently characterized in the laboratory using standard and infrared analysis. The results obtained showed that IRS technique is able to provide qualitative information both about the process and pomace composition. Moreover, models for the prediction of the main quality parameters of pomace were developed. Considering the importance of the Italian olive oil sector the application of IRS for the assessment of biomass quality could be very useful; in this way the use of this residual is encouraged and the olive oil production chain acquires greater sustainability increasing the added value of the product itself.

\section{APPLICATION OF PROXIMAL AND REMOTE SENSING ON PRECISION VITICULTURE IN SARDINIA (ITALY) - PRELIMINARY RESULTS}

Filippo Gambella, ${ }^{1}$ Antonio Dore,${ }^{2}$ Viviana Guido, ${ }^{1}$ Luisella Sistu, ${ }^{1}$ Davide Piccirilli, ${ }^{1}$ Maria Giovanna Molinu, ${ }^{2}$ Maria Caria, ${ }^{1}$

Antonio Pazzona ${ }^{1}$

${ }^{1}$ Università degli Studi di Sassari, Dipartimento di Agraria, Sezione di Ingegneria del territorio, Sassari, ${ }^{2}$ Consiglio Nazionale delle Ricerche, Istituo di Scienze delle Produzioni ALimentari CNR-ISPA Sassari, Italia E-mail gambella@uniss.it

Key words: proximal sensing, Multiplex $3{ }^{\circledR}$, total anthocyanin, $c v$ Cagnulari, Sardinia.

The colored grapes anthocyanins content is a useful tool to allow the decision support system in viticulture. The optical portable sensor Multiplex $3^{\circledR}$ (FORCE-A, Paris, France) is able to screening the colored component of grapes with a rapid and non-destructive method.

Such is based on the transmission of fruit chlorophyll fluorescence in accordance to anthocyanin contents of intact berry skin, therefore some indices that described this phenomenon are ANTH_RG (Anthocyanin excitation in Red-Green fluorescence) and FERARI (Fluorescence Excitation Ratio Anthocyanin Relative Index).

The aim of this study is the calibration of FERARI and ANTH_RG indices in relation to total anthocyanins content ( $\mathrm{mg} / 100 \mathrm{~g}$ skin), obtained by wet chemistry analysis. The trial was carried out in two Cagnulari vineyards in the Northern Sardinia (Alghero, Sennori). The ANTH_RG and FERARI indices were monitored in the fields, on bunches, during the 2015 season from veraison to harvest.

The FERARI index show a good correlation with the anthocyanin concentration derived from spectrophotometric analysis in both samples (Alghero $\rho=0.69$, Sennori $\rho=0.66$ ), the equation obtained for this index is a logarithmic curve.

The ANTH_RG index show a weak inverse correlation with the anthocyanins measured (Alghero $\rho=-0.24$, Sennori $\rho=-0.23$ ), and the curve that fit as better as possible the data is an exponential.

In conclusion, in this first part of the research, we observed that FERARI index may provide decision supports for precision viticulture. Further studies are oriented to confirm this preliminary results. 


\section{PREDICTION OF PHYSICO-CHEMICAL INDICES IN INTACT OLIVES AND OLIVE PASTE BY MEANS OF VISIBLE/NEAR INFRARED SPECTROSCOPY}

\author{
Valentina Giovenzana, ${ }^{1}$ Roberto Beghi, ${ }^{1}$ Raffaele Civelli, ${ }^{1}$ \\ Serena Trapani, ${ }^{2}$ Riccardo Guidetti ${ }^{1}$
}

${ }^{1}$ Department of Agricultural and Environmental Sciences (DiSAA), Università degli Studi di Milano; ${ }^{2}$ Department of Agricultural

Biotechnology, Food Technology Section, University of Florence, Firenze, Italy

\section{E-mail: valentina.giovenzana@unimi.it}

Keywords: olive, olive paste, vis/NIR spectroscopy, ripening, process control.

The challenge of producing a high quality extra virgin olive oil is of great interest and the selection of olive fruit with defined properties which ensure positive attributes in the olive oil and the real time process control are foreseeable in the production chain.

The investigation of the olives characteristics before the milling process could allow to control the quality of the oil output. A better monitoring of the oil production process also depends on controlling of the paste, the intermediate product between the olives inlet in the process and the oil outlet from the mill, to establish correlations among olives, paste and oil. Nowadays, established methods for quality assessment are generally based on tedious and time consuming techniques that are impractical for processing a big number of samples. Therefore, there is a lack of real time information during the milling process in order to keep monitored the operating parameters.

The aim of the work was the application of vis/NIR spectroscopy in order to correlate the spectral data, acquired on intact olives just before or on pastes during the milling process, to the crucial parameters for the optimization of the milling process.

A total of 54 samples were collected and each sample was composed of $300 \mathrm{~g}$ of olive fruits randomly collected from the selected plants. The olives were collected weekly. Spectral acquisitions were performed using an optical portable system operating in the $400-1000 \mathrm{~nm}$ wavelength range. Two spectral measurements were taken in reflectance mode on individual fruit along their equator region. Physical measurements (yield point force and total deformation energy) were performed on olives samples, while, after fruits crushing for olive paste production, traditional chemical analysis (moisture, oil and sugars content) and maturity index (MI) were measured and correlated to spectral data. The correlations between spectral data and chemical parameters were carried out also considering the spectra acquired on olive pastes. The olive samples available were used for the calculation of a chemometric regression model for reference parameters by using the partial least squares (PLS) regression analysis. The vis/NIR spectra acquired on single olive were correlated to the texture parameters (one-to-one correlation) using the PLS regression algorithm, while the 30 olive spectra representing each experimental sample were averaged and the resulting mean spectrum was correlated to the chemical indices and MI. Similarly, olive paste samples were also correlated to chemical reference data and to MI to create PLS models. The obtained results were encouraging whether for chemical, texture and MI parameters. The study showed the feasibility of real time prediction of important indices. The sector could be helped by the adoption of rapid analytical systems for olive fruits and olive paste for a quick evaluation of crucial features in a view of a better control of the milling process.

\section{NEW STATISTIC TOOLS FOR SOMATIC CELL MONITORING: A STUDY APPLIED TO SHEEP MILK}

Djangsou Hagassou, Giovanni Chessa, Maria Caria, Elena Brundu, Viviana Guido, Antonio Pazzona

\section{Dipartimento di Agraria, Università degli Studi di Sassari, Italia \\ E-mail dell'autore di riferimento: dhagassou@uniss.it}

Keywords: SCC, EC, lactose, first screening system, smart tools.

Support Vector Machines (SVMs) are tools for statistical pattern recognition, focusing on algorithms capable of learning and adapting the structure of the input parameters by using a training process based on a raw dataset. SVMs have been applied in numerous real-world sectors such as medical diagnosis, bioinformatics, image processing and text mining. In biomedical sector SVMs have shown promising disease detection effectiveness and helped to increase the objectivity of decision-making process.

In an attempt to verify the applicability of SVMs in detecting udder inflammatory status in Sarda dairy ewes, three milk parameters such as electrical conductivity (EC), lactose and somatic cell count (SCC) were considered and their classification characteristics (sensitivity, specificity, positive error rate, negative error rate and test accuracy) have been assessed.

Data used in this investigation were obtained from a ten-year historical database of milk analysis performed by ARAS (Associazione Regionale Allevatori della Sardegna) Laboratory. Milk samples were collected from a number of flocks distributed all over the Sardinian region.

In order to find the best thresholds of lactose and electrical conductivity to discriminate between healthy and inflammatory udder status, it was chosen a SCC threshold of $700 \times 10^{3}$ cells/ml, which was considered as the optimal upper limit of SCC in healthy Sarda dairy ewes by previous authors.

To develop and assess the SVMs model performance, Rstudio 9.1000 was used and the raw data was processed by using the Kernlab package, an S4 package for Kernel methods. A raw data of 6190 milks samples from individual udder half was divided into training dataset (5571 milk samples) and test dataset (619 milk samples).

Applying the ROC curve methodology to our raw data and using EC and lactose as predictive variables and SCC as classification variable as reported by the previous authors, following classification characteristics were highlighted: considering EC and SCC, sensitivity, specificity and associated criterion were $82.47 \%, 59.58 \%$, and $4.75 \mathrm{mS} / \mathrm{cm}$; if lactose and SCC are considered, sensitivity, specificity and associated criterion were $75.26 \%, 73.56 \%$ and $4.84 \%$ respectively.

SVMs classification performance was characterized by the following outputs: sensitivity $75.26 \%$; specificity $73.56 \%$; positive error rate $65.40 \%$; negative error rate $5.88 \%$; test accuracy $73.83 \%$. Therefore, the results of this investigation lead us to consider that SVMs could be used as a potentially valuable alternative approach for early detection of the udder inflammatory status in Sarda dairy ewes by integrating on automatic milking machines the EC and lactose sensors and recording data daily. It is well-known that the early detection of subclinical mastitis is of great importance for animal healthcare and flock management allowing to promptly isolate the infected animals and guaranteeing the milk yield and quality. In addition a well-timed veterinary intervention on the infected animals can increase the cure rate. 


\section{DESIGN OF AN AUTOMATIC MACHINE FOR VARIABLE RATE APPLICATION OF FLAME WEEDING ON MAIZE}

Luisa Martelloni, Christian Frasconi, Marco Fontanelli, Michele Raffaelli, Michel Pirchio, Andrea Peruzzi

\section{Dipartimento di Scienze Agrarie, Alimentari e Agro-ambientali, Università di Pisa, Italia \\ E-mail: Imartelloni@agr.unipi.it}

Key words: precision agriculture, site-specific weed control, variable rate application, mechanical and thermal control.

An automatic operative machine for variable rate application (VRA) of flame weeding on maize was designed and built at the University of Pisa within the European Project "Robot fleets for Highly Effective Agriculture and forestry management" (RHEA). The machine was designed to conduct non-selective mechanical weed control between the crop rows and site-specific VRA of flaming in the intra row space. Flame weeding is applied by a pair of burners liquefied petroleum gas (LPG) fed, which work cross to the row, and is activated automatically only in presence of weeds. The machine was coupled with an autonomous tractor equipped with an optical sensor for real-time row crop and weed detection. Specific hardware and software provide information about the weed cover percentage detected and send these data to the operative machine. The LPG dose that has to be applied is chosen in real-time between two doses identified in the calibration phase to be effective on weed cover percentages lower or higher than $25 \%$. In the case of $0 \%$ weed cover, burners are switched off. The burners ignition system was designed to be almost instantaneous in order to minimize all delays, which elapse between weed detection and the presence of the flame in the area that have to be treated. The almost instantaneous burners ignition system allows also to avoid the use of a pilot flame, which would be switched on for all the effective working time of the machine. The operative machine is equipped with and automatic steering system, which according to directional movement of two metallic wheels, allows maintaining the same trajectory of the autonomous tractor, and avoiding the accidental damage of the crop. A study aimed to find the optimal LPG doses for an effective weed control and which not lead to yield losses, as a consequence of damages occurred to maize plants treated at different development stages, was conducted in 2012 and 2013 at the experimental farm of the University of Pisa. Maize and weeds response to the application of five LPG doses was evaluated in terms of yield, weed density after the application and weed dry biomass at harvest. The optimal LPG doses estimated were useful for the automatic operative machine calibration. The site-specific VRA of flaming and the use of an almost instantaneous burners ignition system allow to reduce the LPG consumption compared to a continuous application and the presence of the pilot flame during turning, leading to a reduction of costs for the thermal weed management of heat-tolerant crops. The operative machine represent a new technology for precision agriculture, which if integrated with a proper perception system, independent from the autonomous tractor for the receiving of information needed for the automatic regulation of the LPG dose, could work coupled with a common tractor.

\section{TUNING A TERRAIN FOLLOWING REMOTELY PILOTED AIRCRAFT SYSTEM FOR CROP MONITORING IN PRECISION AGRICULTURE}

\section{G. Ristorto, ${ }^{1}$ G. Guglieri, ${ }^{2}$ F. Quagliotti, ${ }^{2}$ F. Mazzetto ${ }^{1}$ \\ ${ }^{1}$ Facoltà di Scienze e Tecnologie, Liberà Università di Bolzano; ${ }^{2}$ Dipartimento di Ingegneria Meccanica e Aerospaziale, Politecnico di Torino, Italia \\ E-mail: gianluca.ristorto@unibz.it \\ Key words: Remotely Piloted Aircraft System (RPAS), Optical Sensors, NDVI, Crop Monitoring, Precision Agriculture.}

Remotely Piloted Aircraft Systems (RPAS), generally known as drones, are very promising in environmental monitoring and they has a very high technological level to apply them in reconnaissance mission with an high level of automation in order to reduce the workload of the operators. In the next 10 years, over $75 \%$ of existing RPAS will be used for crop monitoring in precision farming, where prompt management reactions to plant disease, lack of plants nutrients and environmental changes are the focal point to farm efficiency and productivity.

In order to optimize the RPAS monitoring activities in terms of time (process automation) and in term of costs (economic sustainability), planning the reconnaissance operations is crucial: every single procedure to accomplish the survey mission must be examined and evaluated. Furthermore, we have to consider the Italian Regulation on RPAS that introduces restrictions on RPAS operations.

Different kind of sensors can be used for crop monitoring and each sensor has a specific mission profile. Active sensors require a very low flight (within 2 meters above the ground) and a commercial RPAS cannot achieve this performance. Passive sensors require a very high overlap (over 70\%) of the images.

In this work we present the results of the analysis of monitoring performances of RPAS, in terms of workrate (ha per day) and a cost estimation ( $€$ per ha). In this analysis, we considered two different kind of commercial sensors. We show the calibration test performed to achieve the very low level flight, the validation of the performances, the repeatability of the flight path and the validation of sensors measurements. 


\section{STUDIES AND DEVELOPMENT OF A TERRESTRIAL MOBILE LIDAR SCANNING FOR CANOPY SHAPE ASSESSMENT}

\author{
Daniele Sarri, ${ }^{1}$ Riccardo Lisci,1 Marco Rimediotti, ${ }^{1}$ Marco Vieri, ${ }^{1}$ \\ Jorge Martínez Guanter, ${ }^{2}$ Manuel Pérez-Ruiz, ${ }^{2}$ Juan Agüera Vega ${ }^{3}$ \\ ${ }^{1}$ Department of Agriculture, Food production and Forestry manage- \\ ment, Division Biosystems Engineering, University of Florence, Firenze, \\ Italy; ${ }^{2}$ Department of Aerospace Engineering and Fluids Mechanics, \\ University of Seville, Seville, Spain; ${ }^{3}$ Department of Rural Engineering, \\ University of Córdoba, Spain \\ E-mail: daniele.sarri@unifi.it
}

Key words: VRT, laser scanner, precision agriculture, spraying.

Remote sensing technologies are spreading rapidly such as combination of decision support tools for farm management. Between emerging solutions, LiDAR technology(Light Detection and Ranging) appears like more responsive to the specific and heterogeneous demands of the agricultural sector. The LiDAR, basically made by a laser sensor, measures the distance between it and a generic target without geographical positioning reference at the platform (terrestrial or aerial) where is coupled. The operating principle is based on the time of flight of a pulse i.e. the timeframe interval needed so that a ray of light (infrared region), generated by an emitter, hit a target and its reflections are intercepted by a receiver. The values, calculated through stabilized quartz clock, allow to achieve the distance of everyone points and schematize the relative coordinate $(x, y, z)$. The overall results is the acquisition of millions points arranged in irregular clouds that individuates exactly (possibility of 2D and 3D modeling) the target shape. These features, together the quick management, make it a usable tool in several operative contexts ranging from environmental monitoring, the architectural survey, civil engineering and today the agricultural sector. In this context, and in the much more generally precision agriculture domain, terrestrial LiDAR may become an effective aid to the characterization and analysis of plants growth. The knowledge of such parameter is one of the constraint for the sustainable management which takes into account the sitospecific requirements and variability (growth / yield / failed areas etc.) within the production units. Nevertheless, to date, there are only limited knowledge that allow LiDAR data elaboration into prescription maps and/or specific rules for devices management in order to get a variable rate treatment. One example of this is the possibility to varying plant protection products doses and volumes rates in relation to the target volume. The generalised usage of LiDAR technologies may potentially bring many advantages and more generally toward the increasing of the economic and environmental sustainability. On these considerations, the study focuses to the development and implementation of a ground monitoring system able to manage and process data generated by terrestrial laser scanner in order to estimate the crown volume of the plants. To this end, some preliminary tests in an experimental olive grove located in Tuscany (Italy) conducted in collaboration with the Department of Aeroespacial Ingeniería y Mecánica de Fluidos, Área de Ingeniería Agroforestal the University of Seville, were carried out. Preliminary results, achieved by comparing digital LiDAR data versus volume measurements made manually or through photogrammetric analysis, have provided significant results and the broad potential of this technology.

\section{AGRICULTURE 3.0}

Marco Vieri, Riccardo Lisci, Marco Rimediotti, Daniele Sarri

Department of Agriculture, Food production and Forestry management, Division Biosystems Engineering, University of Florence, Firenze, Italy

E-mail:marco.vieri@unifi.it

Key words: innovations, precision agriculture, smart technologies, knowledge platforms.

Recent developments on the adoptable agricultural sciences, within the chaotic proposal scenario, have highlighted the chance of a paradigm change for the production setting. In industry it talks about "industry 4.0" paradigm based on nine different technologies at service of an enterprise: cyber security, big data, augmented reality, radio frequency identification, tracking, 3D print connected to plants, rapid prototyping, cloud computing, robotics. Industry 4.0 means real time network connections of humans, machines and objects with the intelligent system management. It is about of integrated network systems, hardware and software (Cyber-Physical-Systems) that communicate and actively operate in the internet of things. Precision agriculture, that since ' 90 mechanical agrarian science has been developed, appears to date in line with the industry sector evolutions and characterized by a strong interdisciplinary approach and convergence of technologies that stem from different sectors. In this quickly and continuous evolutionary scenario, we are perhaps arrived, after the "Illuminismo period" which has provided new tools and machines that could increase the quality and quantity of work and successively to the "green revolution" characterized by simplification and exploitation in order to tackle the population needs, on the dawn of the third agricultural Anthropocene revolution. The "era" where man and his activities are responsible of the major causes of territorial changes, structural and on climate. 3.0 agriculture could be representative of the "third agrarian revolution" inducted by new technologies and structured on a renovated respect towards human, environment, food and even on the discovering of agrarian discipline complexity. The new paradigm consist in a newly found complex knowledge, allowed today by whole thing of aids that induced an augmented skill and potentially an open source and enlarged intelligence available in any place and for any production segment. Agriculture 3.0 will be a real revolution to the extent that will create a steady pulse broadening of knowledge and its useful and sustainable application: precision agriculture and also agriculture 3.0 can orient themselves on the services and then to a speculative potential concentration of knowledge implemented by low profile operators. The real revolution will be the ability to create freedom development of knowledge and entity, that as the Renaissance workshops, have the chance to create free enterprises and schools-companies-shops of excellence in the territory, entrusted to the great capacity of the "genius loci ". It must therefore start from education and by free and agile structures of knowledge and experimentation (such as the FabLab). "Educational at the innovation" is the key that can make effective this evolution: a growth that must be shared, inclusive, participatory between all actors of the rural sector, of any segment and especially in view of using and acquiring of those aspects of "resilience" that the economic and climate change require. 
WORK ORGANIZATION , LOGISTICS AND QUALITY IN AGRICULTURAL AND FORESTRY SECTORS

\section{THE NEW STANDARD METHOD ISO 22401 TO CLASSIFY FIELD CROP SPRAYERS ACCORDING TO SPRAY DRIFT USING AN AD HOC TEST BENCH}

Paolo Balsari, Paolo Marucco

Università di Torino, Dipartimento di Scienze Agrarie Forestali e Alimentari (DISAFA),Grugliasco (To), Italia

E-mail:paolo.balsari@unito.it

Key words: boom sprayer, drift, nozzle, boom height.

Measurement of spray drift generated by field crop sprayers, made in the field following the only standardised methodology actually available (ISO 22866), requires long time for the execution of tests and provides results that are strongly affected by the variable environmental conditions and are therefore poorly reproducible. Some years ago the research team Crop Protection Technology at DiSAFA - University of Torino started to study easier and quicker alternative test methods, enabling to assess the amount of spray drift generated by the different types and settings of boom sprayers actually available on the market, in order to classify them according to drift risk. These studies lead to the development of an ad hoc test bench for the assessment of spray drift generated by field crop sprayers. With the aim to consolidate the test methodology based on the use of this specific test bench, to verify its applicability in order to classify the equipment according to drift risk and, finally, to publish it as International Standard, experimental tests were carried out inside a shed comparing different settings of a mounted boom sprayer (Delvano HD3) equipped with a $15 \mathrm{~m}$ boom and a tank of $800 \mathrm{l}$ nominal capacity. Working indoor allowed to operate the tests in very similar environmental conditions and therefore to make an objective comparison of the results obtained. The test bench is made of an aluminium frame $10.5 \mathrm{~m}$ long and $0.5 \mathrm{~m}$ wide equipped with slots for the spray drift collectors that are positioned every $50 \mathrm{~cm}$ along the bench. These slots are equipped with a sliding cover which remains close during the pass of the boom sprayer with the activated nozzles over the test bench and then, thanks to a pneumatic system, simultaneously reveals the collectors just after the boom sprayer pass, so to assess the amount of droplets which remains suspended in the atmosphere behind the sprayer and falls out after the sprayer pass, that is considered as potential spray drift. During the trials the test bench was positioned parallel to the sprayer forward direction, in correspondence of the middle of the right half boom. Eight different boom sprayer settings were examined, combining three different nozzle types (conventional flat fan TeeJet XR 11004, air induction flat fan Agrotop TDXL 11004 and centrifugal Micromax 3) and three different boom heights $(30,50$ and $70 \mathrm{~cm})$. The sprayer setting featured by the use of conventional flat fan nozzles XR 11004 at $50 \mathrm{~cm}$ height was established as reference for the classification of the results obtained.

Experimental results pointed out the effect of the nozzle type and of the boom height on the amount of potential spray drift measured on the test bench and therefore fully confirmed the possibility to apply this test method, that now has been officially standardised as ISO 22401, for classifying field crop sprayers according to the spray drift generated, following to the criteria reported in the ISO Standard 22369-1.

\section{ASSESSMENTS OF THREE MAIZE STALKS HARVESTING CHAINS FOR THEIR ENERGETIC VALORIZATION IN ANAEROBIC DIGESTION PLANTS}

\author{
Paolo Balsari, Gianfranco Airoldi, Elio Dinuccio
}

Università di Torino, Dipartimento di Scienze Agrarie Forestali e Alimentari (DISAFA), Grugliasco (To), Italia

E-mail:paolo.balsari@unito.it

Key words: by-products, maize stalks, biogas, harvesting chains.

Three harvesting chains (HC) for maize stalks energetic valorization in anaerobic digestion plants were assessed and compared. Trials were carried out on a FAO 600 class maize hybrid planted at an irrigated arable area of western Po Valley. In all three scenarios combines with traditional concaves and 8 rows heads ( $6 \mathrm{~m}$ working width) were used. In $\mathrm{HCl}$ it was used a combine fitted with a harvester head able to pick up the whole maize plant and a device to chop the material leaving sieves and straw walker. The chopped material was blown on a trailer towed by a tractor moving aside the combine. In HC2 and HC3 a partial harvest of the stovers (mainly represented by cobs and husks) was carried out. With special regards to HC2 harvesting was performed by a combine with conventional head - equipped with stalk rollers - and a device to carry the material leaving straw walkers and sieves into the compression chamber of a baler. The latter was towed and powered by the combine itself.

In HC3 a combine fitted with a conventional head and a device to chop the material leaving straw walker and sieves and to blow it on a trailer towed by a tractor aside the combine was used. The material harvested by $\mathrm{HCl}$ and $\mathrm{HC} 3$ was piled into a bunker silo. The squared bales harvested with HC2 were wrapped with plastic sheets and then stacked on a concrete platform.

For each harvesting chain field capacity, direct and indirect machines and implements energetic costs were determined. The biomethane potential (BMP) of the harvested material was also measured according to VDI 4630 standard methodology.

The $\mathrm{HCl}$ allowed to collect $21.2 \mathrm{Mg} / \mathrm{ha}$ of biomass. The latter consisted of $59.2 \%$ stalks, $17.8 \%$ cobs and $23.0 \%$ husks and leaves. The dry matter (DM) content of the harvested biomass was $44.9 \%$, with a volatile solids (VS) content of $94.7 \%$. With both HC2 and HC3 the same amount of biomass $(3.8 \mathrm{Mg} / \mathrm{ha}$ ) was collected. Nevertheless, the stover composition slightly differed: $62.8 \%$ DM with a VS content of $96.8 \%$ for HC2 and $62.0 \%$ DM with a VS content of $97.0 \%$ for HC3. The cob incidence on DM was higher than $60 \%$ in all cases.

The biomethane potential of the harvested biomass corresponded to $81.4 \mathrm{GJ} / \mathrm{ha}$ and $3.7 \mathrm{GJ} / \mathrm{Mg}$ (wet basis) for $\mathrm{HC1}, 23.1 \mathrm{GJ} / \mathrm{ha}$ and $5.8 \mathrm{GJ} / \mathrm{Mg}$ (wet basis) for HC2 and $21.1 \mathrm{GJ} / \mathrm{ha}$ and $5.7 \mathrm{GJ} / \mathrm{Mg}$ (wet basis) for HC3. The highest energetic cost (5.2 $\mathrm{GJ} / \mathrm{ha}$ ) for the harvest and the storage of the material was calculated for the $\mathrm{HC} 1$ scenario followed by $\mathrm{HC} 2$ (3.8 GJ/ha) and HC3 (2.8 GJ/ha). Nevertheless, the latter values correspond respectively to the $6.6 \%, 16.7 \%$ and $13.4 \%$ of the energetic content of the harvested material. Thus, in terms of energy balance, the $\mathrm{HCl}$ showed to be most efficient scenario. 


\section{PRE-TREATMENTS OF RICE STRAWS TO INCREASE THEIR BIOGAS POTENTIAL}

Paolo Balsari, Elio Dinuccio, Dalibor Cuk, Luca Rollè, Fabrizio Gioelli

Università di Torino, Dipartimento di Scienze Agrarie Forestali e Alimentari (DISAFA), Grugliasco (TO), Italia

E-mail: paolo.balsari@unito.it

Key words: Agricultural by products, rice straw, biogas, ammonia, pretreatments.

The increase in energy demand, the reduction of fossil fuels availability and the general concern about greenhouse gas emissions to air have led to international agreements for renewable energy production. The European Union with the Directive 2009/28/EC established as a common objective the enhancement of renewable energy production. Each Member State has a target calculated according to the share of energy from renewable sources in its gross final consumption for 2020. The Italian target has been set to $17 \%$. Between the current technologies for renewable energy production, the Italian anaerobic digestion (AD) sector has boomed in the last years. More than 1600 installations are currently into operation with approximately $1 \mathrm{GWel}$. installed power The majority of biogas plants (88\%) are fed with mixtures of manure, agro-foodstuff by-products and large amounts of energy crops (Fabbri et al., 2013). Nevertheless, feeding AD plants with energy crops cause a reduction of the technology environmental sustainability as demonstrated by Dohler et al. (2009). Producing, harvesting and transporting these biomasses are responsible of up to $60 \%$ of the $\mathrm{CO}_{2 \mathrm{eq}}$ emissions produced by the whole production chain. For this reason a recent Ministerial Decree (6 luglio 2012) incentivized the replacement of energy crops with agricultural by-products in the feeding mixture. At present, large quantities of agro-industrial by-products have no market and are destined to landfill or, as in the case of cereals straw, remain in the fields after harvesting operations (ITABIA, 2003). The national cereal sector produces large amounts of byproducts as maize stalks and straw. In the Piemonte Region 110.000 ha are dedicated to rice cultivation. The average rice straw production is estimated in $300 \mathrm{Mt}$ of dry matter per year. Currently straw is incorporated into the soil, used as bedding material or burned in power stations. Due to its ligno-cellulosic structure, rice straw is characterized by a low biologic degradability. Thus, it's not commonly used as a feedstock for anaerobic digestion plant. The DISAFA Waste Management Group has performed some field and laboratory scale trials to assess the efficacy of chemical, mechanical and thermal pre-treatments to increase the rice straw degradability and its biomethane potential. Rice straw was harvested by a roundbaler at a rice farm located in Vercelli Province. Bales were afterwards wrapped by plastic sheets and chemical pre-treated by injecting ammonia within each bale (with three replicates) at two rates: $2 \%$ and $4 \%$ (w/w calculated on the straw dry matter content). Untreated straw bales were left untreated and used as control. After six months, the straw was collected and subjected to further mechanical (chopping), thermal (pressure cooking) and combined pre-treatments. The biological methane potential (BMP) of treated and untreated samples was afterwards assessed by laboratory scale batch assays according to the VDI4630 methodology. Results showed that the straw chemical, mechanic and thermal pretreatments alone can enhance the straw BMP by $45 \%, 30 \%$ and $20 \%$ respectively. The combined effect of thermal and mechanic treatments resulted in a 30\% BMP increase, whereas the combination of chemical and thermal pre-treatment showed an inhibiting effect on the methane yield.

\section{THE IMPACT OF TRAINING ON THE RISK PERCEPTION OF AGRICULTURAL WORKERS}

\author{
Massimo Cecchini, Danilo Monarca, Andrea Colantoni, \\ Benedetto Baciotti, Roberto Bedini, Filippo Cossio
}

\section{Department of Agricultural and Forestry Sciences, University of Tuscia, Viterbo, Italy}

E-mail: cecchini@unitus.it

\section{Key words: training and information, foreign workers, safety and health.}

This paper presents the results of a survey on the incidence of training on farmers' risk perception, with particular reference to their different nationalities.

The study started from a research on training needs for workers carried out on farms of the Lazio Region (Italy). Subsequently training courses were done, each one lasting 10 hours, for groups of workers from different countries (Italy, India, Romania), with the presence of native teachers in the classroom and the availability of teaching materials in different languages.

The research on the training needs was based on the study of the distribution of different crops in the region, and on the analysis of accidents and occupational illnesses data in agriculture in Lazio. It was also developed a specific questionnaire submitted to a sample of farms of the same territory.

The collection of data on risk perception has been made possible thanks to the use of another questionnaire, regarding the risk perception, submitted to a sample of 99 workers at the beginning and end of the training courses.

Previous researches by the same authors showed that risk perception is related to having or not attended training courses on safety and health at work, but also those who result having attended safety courses do not always implement safe behaviors.

Among the populations of the analyzed samples, in particular for the Italian and Romanian ones, there is a basic and insufficient culture of safety at work; this behavior is less evident for Indian workers. The general index of risk perception, on the basis of the results of questionnaires submitted to workers before their participation to the training course on Safety and Health at Work, shows that the values for Italian and Romanian workers are respectively $53.1 \%$ and $42.9 \%$, while for Indians the value is $78.6 \%$. Therefore $46.9 \%$ of the Italian sample, $57.1 \%$ of the Romanians and $21.4 \%$ of the Indian sample does not care to safety at work and / or show uncertainty.

Following the participation in the training course on health and safety at work, it is observed an appreciable average increase in risk perception of about $17.1 \%$.

\section{VEHICLE ROUTING AND SCHEDULING PROBLEM: A SOFTWARE FOR THE OPTIMIZATION OF SHEEP MILK COLLECTION}

Giovanni Chessa, Maria Caria, Giuseppe Todde, Lelia Murgia, Antonio Pazzona

Dipartimento di Agraria, Università degli Studi di Sassari, Italia

E-mail: giovachessa@uniss.it

Key words: Travelling Salesman Problem, logistics, Ant Colony Optimization, milk.

The rising costs of milk collection incurred by the dairy processing industries has caused a particular interest in the optimization of the routing and scheduling of vehicles (VRS), particularly in the sheep and goat sector. In Sardinia, the organization of the transport of milk from 
farms to the cheese factories is affected by severe deficiencies in the rural road network and by the farm fragmentation. The vehicles routing and scheduling problem (VRSP) deals with the optimization of the total transportation cost under certain constraints condition, as distance, time windows, tank vehicles capacities.

In this study the organization of milk collection of a cheese industry (Industria Casearia F.lli Pinna, Thiesi) was analysed and redesigned using a software, called MilkTour, developed by the Department of Agraria of Sassari University for the optimization of sheep milk collection. The study involved 87 sheep farms and 5 collection routes, each of them spread over a distance of 138-220 km and collecting 6,500 l on average. All 87 farms were geo-localized using the open source application GPS-Logger, recording the routing time and the milk collected.

The software MilkTour has optimized 4 out of 5 routes leading to a positive effect on the decrease of the cost per litre of milk collected ($0.21 €$ cent $/ /$ on average). Among the new routes, route 1 was reduced by $17 \mathrm{~km}$, which is equivalent to more than $3,600 \mathrm{~km}$ in one year. The shorter distance covered by each vehicle affects not only the transport costs but also the $\mathrm{CO}_{2}$ emitted from the fuel combustion. The best cost savings were found for route 2 that achieved $3,700 €$ per year. Another important result of the study was the high correlation between the milk collection density $(\mathrm{l} / \mathrm{km})$ and the cost per litre of milk collected (€cent/l), which allows to make a first evaluation about the results of the optimization process and also address the organization choices when planning new routes.

\section{PROPAGATION OF NOISE BY HELICOPTER LOGGING OPERATION IN NATURAL ENVIROMENTS}

Stefano Grigolato, ${ }^{1}$ Andrea Rosario Proto, ${ }^{2}$ Omar Mologni, ${ }^{1}$ Giuseppe Zimbalatti, ${ }^{2}$ Raffaele Cavalli ${ }^{1}$

${ }^{1}$ Department of Land, Environment, Agriculture and Forestry, Università degli Studi di Padova; ${ }^{2}$ Department of Agraria, Università Mediterranea di Reggio Calabria

\section{E-mail:stefano.grigolato@unipd.it}

Key words: helicopter logging; noise propagation; logistic; GIS modelling.

The use of helicopters for logging extraction has received some attention in the recent years also in the Italians Alps as an alternative to cable extraction in the case of long extraction distances coupled with terrain obstacles.

By contrast helicopter logging rises discussion about environmental noise propagation especially when logging is performed in proximity of Sites of Community Importance (SCIs) or Special Areas of Conservation (SACs). In the last decades some researches have focused just on noise propagation in logging operation generated by heavy- and medium-lift helicopters, the first type commonly used in North America and the second one quite common in the central part of the Alps. There is so a lack of information about the intensity of potential noise and its propagation across natural environments generated by light-lift helicopters (maximum payload of 1.5 tons) which are the most used in the Italian Alps. As a consequence, the purpose of this study is to evaluate the potential area of influence of light-lift helicopter logging by performing a noise propagation analysis.

The case study will consider an extraction operation in a coppice stand for firewood production located within a SCI-SAC area in the Eastern part of the Italian Alps.

In order to monitor simultaneously helicopter position and sound pressure in the surrounding forest area, a specific data collection protocol synchronizing the GPS position of the helicopter and different sound level meter data installed in the study area will be developed. In addition, the study will analyse the noise propagation by recording different samples of the sound pressure across the frequency spectrum.

The obtained data will consequently be used as inputs for a noise spreading model for modelling noise propagation in natural environments specifically developed in GIS environment.

\section{ANALYSIS OF TWO VEGETATION MAINTENANCE OPERATIONS IN A HISTORICAL PARK IN FLORENCE}

Lorenzo Guerrini, ${ }^{1}$ Ciro Degli Innocenti, ${ }^{2}$ Antonio Guiso, ${ }^{1}$ Fabio Baldi, ${ }^{1}$ Alessandro Parenti ${ }^{1}$

${ }^{1}$ Dipartimento di Gestione dei Sistemi Agrari, Alimentari e Forestali, Università degli Studi di Firenze; ${ }^{2}$ Comune di Firenze, Quartiere 5, Via F. Baracca, 150/P, 50127 Firenze, Italia

\section{E-mail: lorenzo.guerrini@unifi.it}

Key words: lawn mowing, hedge pruning, urban green maintenance

The management of a historical park requires a maintenance plan for yearly and for multi years operations. Every year, small plants, playgrounds, furniture and small buildings require maintenance operations. On the other hand, trees, building, lighting systems, irrigation systems etc., require maintenance every few years. Among the yearly maintenance operations of Villa Strozzi park (Florence, Italy) we choose and analyze two of the more time requiring: lawn mowing and hedge pruning.

Lawn mowing has been monitored in three areas with a surface of $5585 \mathrm{~m}^{2}, 3871 \mathrm{~m}^{2}$ e $3968 \mathrm{~m}^{2}$. The areas have been characterized for the following parameters: slope, obstacles presence/absence, herbaceous species and their height and moisture before the mowing. During tests two mowing operations and two different machines (with a manual 2stroke engine brush cutter for finishing) have been tested. The analysis has been carried out considering the overall work time, the average speed of the mowers, the effective cutting width and the consumed energy for the operation. Furthermore the average grass height and its variability after the cut have been considered as a parameter for the measurement of the operation quality.

Mowing conditions and working area affect the time required for the work. It ranged between the minimum of $56.3 \mathrm{~m}^{2} / \mathrm{min}$ and the maximum of $81.75 \mathrm{~m}^{2} / \mathrm{min}$. Consistently, energy consumptions ranged between the minimum of $0.012 \mathrm{MJ} / \mathrm{m}^{2}$ and the maximum of 0.041 $\mathrm{MJ} / \mathrm{m}^{2}$. On the other hand, the brush cutter worked at the constant value of about $8.0 \mathrm{~m}^{2} / \mathrm{min}$.

The tests performed on the hedges have been done on two different hedges. They differ in time from the last pruning: 18 months and 12 months. Each hedge was divided in to 4 segments of $20 \mathrm{~m}$ each. Two different hedge trimmers have been tested: an electric trimmer and a 2-stroke engine trimmer. First of all, the following parameters have been measured: working times, removed biomass, energy consumption. Then, a methodology for the evaluation of the working quality of trimmers, based on visual assessment on the cut area, has been developed.

The time required for the pruning of $1 \mathrm{~m}$ of hedge was about $30 \mathrm{~s}$ for both machines. On the other hand, energy consumptions were strongly different. The electric trimmer required $2.73 \mathrm{KJ} / \mathrm{m}$ while the 2 -stroke one $111.03 \mathrm{KJ} / \mathrm{m}$. Cut quality was not affected by the used hedge trimmer. 0 the other hand, the 18 months hedge was less damaged by the cutting than the 12 months one. 


\section{ANALYSIS AND GUIDELINES OF THE BAKING PROCESS FROM ANCIENT GRAINS FLOUR}

Lorenzo Guerrini, ${ }_{1}^{1}$ Giulia Angeloni, ${ }^{1}$ Fabrizio Nistri, ${ }^{2}$ Paolo Spugnoli, ${ }^{1}$ Alessandro Parenti ${ }^{1}$

${ }^{1}$ Department of Management of Agricultural, Food and Forestry System, University of Florence; ${ }^{2}$ Tecnologie per l'arte bianca di Fabrizio Nistri and C. Sas, Prato, Italy

E-mail: lorenzo.guerrini@unifi.it

Key words: weak flours, alveograph, mixers

Ancient wheats have been introduced back in the bread-making process for their health and nutritional properties. Their cultivation was abandoned for more protein cultivars, which show higher yields and they are easier to be processed. Contrarily, the flours from ancient wheats have low technological indexes. Hence, they have low attitude to the bread-making and, therefore they require the development of suitable processing protocols.

In this job some steps of the process of bread-making have been analyzed with the purpose to furnish some operational guidelines to produce bakery products with flours of ancient wheats.

The process of bread-making have three main steps: mixing of the ingredients (kneading phase), leavened and baking.

During the kneading flour, water, and other ingredients are homogenized up to produce an uniform and coherent gluten structure. The development of the dough is a dynamic process, in which the viscoelastic properties changes continuously thanks to the introduction of mechanical energy in to the system. The kind of kneader, time and temperature play a fundamental role for the final mix, in relationship to the type of product that subsequently it be have to realize. For this reason, a study has been carried on with the objective to characterize with the ancient variety, three of the most diffused kneaders: spiral, fork and plunging arms. Three different kneaders were tested at 4 different mixing times in 3 replicates, following a standard recipe. During the phase of kneading alveographics parameters have been monitored as well as the temperature by thermal imaging. Furthermore, temperature have been measured with a probe during the phases of leavening and baking. Subsequently, the breads have been tested for: height, weight, water activity and texture, in a period of storage between 2 and 9 days. In the phase of kneading all the kneaders have made to record an increase of temperature: the fork of around $5{ }^{\circ} \mathrm{C}$, the plunging arms of around $6{ }^{\circ} \mathrm{C}$ and the spiral of around $11^{\circ} \mathrm{C}$. The increase of temperature of the spiral results in a leavening temperature $1.5^{\circ} \mathrm{C}$ higher than the other mixers. At the alveographics tests the fork kneader showed higher values of index of strength (W), higher index of swelling, and higher relationship between tenacity and extensibility. The physical measures have shown the greatest values after 23 min for the spiral, after $36 \mathrm{~min}$ for the plunging arms and after $55 \mathrm{~min}$ for the fork. Thus, fork kneader produce a dough with higher $\mathrm{W}$ value than the others, and produces the more strength dough from the weak flour. On the other hand, the fork kneader was the mixer required the longest process time.

\section{FEATURES OF THE CABLE CRANES AVAILABLE IN THE EUROPEAN MARKET AND CURRENT ALLOCATIONS OF FOREST ENTERPRISES IN THE ITALIAN CENTRAL ALPS}

Omar Mologni, Stefano Grigolato, Raffaele Cavalli

${ }^{1}$ Department Land, Environment, Agriculture and Forestry, University of Padua, Italy

E-mail corresponding author: omar.mologni@studenti.unipd.it

Key words: Cable crane, Market, Forest enterprises, Italian central Alps.

Cable cranes are often the only technically and economically feasible extraction system in low-density forest road conditions and steep slopes. Given the great importance of this extraction system in mountainous areas' forest operations and the recent spread of a number of innovative technical solutions, the present work aims to analyse the technological offer of these machines in the European market and in particularly in the Alpine one. The collection of the data on the machines currently in production will be implemented through consultation of the catalogues (printed and online) and subsequent verification of the information directly from the manufacturing companies. The compilation of the technical information will be organized in a specific database and the catalogued machines will be divided according to technological and functional criteria, identifying different categories in terms of types of installations, size, and power. In order to understand which of the currently available cable crane technology is present in the Alpine area, it will be reviewed the case of the Italian central Alps where actually there are more than 100 forest enterprises with at least one cable crane system. These forest enterprises will be analyzed in terms of adopted cable crane technology; moreover it will be analyzed any correlations with the operating environment, the forest accessibility and the characteristics of the enterprises themselves (size, logistics of the sites, annual volume of processed wood).

\section{HAND-ARM VIBRATION EMISSION OF CHAINSAWS: COMPARISON WITH VIBRATION EXPOSURE}

\author{
Antonio Mantella, Giuseppe Zimbalatti, Andrea Rosario Proto \\ Mediterranean University of Reggio Calabria, Department of Agraria, \\ Reggio Calabria, Italy \\ E-mail: andrea.proto@unirc.it,
}

Key words: risk, vibration, mechanization, chainsaw.

Hand-arm vibration risk is based on the frequency-weighted acceleration total value, given by the root-sum-of-squares of the frequency-weighted acceleration from the three orthogonal axes, x, y and z. For hand-transmitted vibration, the frequencies thought to be important range from about $8 \mathrm{~Hz}$ to $1000 \mathrm{~Hz}$. However, because the risk of damage to the hand is not equal at all frequencies a frequency-weighting is used to represent the likelihood of damage from the different frequencies. As a result, the weighted acceleration decreases when the frequency increases. The eight tools were used, during tests, by a single operator, expert in the use of this typology of tools due to his job activity; the measurements were carried out respecting the indications contained in the provisions UNI EN ISO 5349-1 (2004) and UNI EN ISO 5349-2 (2004). During the tests, several chainsaws types and models were used: Stihl, Husqvarna, Dolmar and Jonsered. The vibration measurement for all activities during which the operator was exposed to the vibration was performed on the test field under controlled conditions. The measurements were carried out on the front and rear handles according to recommendations given in international standard ISO. All the examined chainsaws gave high acceleration values (in a range from 4.7 to $7.02 \mathrm{~ms}^{-2}$ ), but the most restricting data were the daily vibration exposures, calculated considering the real work- 
ing duration time acquired in field, almost ranged between 3.2 and 6.4 $\mathrm{ms}^{-2}$. The results highlighted the high values of acceleration transmitted to the hand-arm system produced by the examined eight chainsaws: the vibration values are greatly higher than the limit ones laid down in the Italian law. The most effective way to prevent vibration reaching worker s hands is to avoid using processes which require workers to hold vibrating surfaces. When the use of vibrating equipment is unavoidable, it is often possible to control the vibration transmitted to the hand.

\section{USING A GIS TECHNOLOGY TO PLAN AN AGROFORESTRY SUSTAINABLE SYSTEM IN SARDINIA}

Giuseppe Pulina, ${ }^{1,2}$ Caterina Canalis, ${ }^{1}$ Cristiano Manni, ${ }^{1,3}$ Antonio Casula, ${ }^{2}$ Luisa Carta, ${ }^{1}$ Ileana Iocola, ${ }^{1}$ Ignazio Camarda ${ }^{1}$

${ }^{1}$ Dipartimento di Agraria, University of Sassari; ${ }^{2}$ Agenzia Forestas, Cagliari; ${ }^{3}$ Corpo Forestale dello Stato, Roma, Italy

E-mail: gpulina@uniss.it.

\section{Key words: Agroforestry, GIS, Sustainability, Sardinia.}

This study was conducted with the aim to quantify the spread of livestock agroforestry in a Mediterranean ecosystem (island of Sardinia, Italy) and evaluate its sustainability in terms of grazing impact. By using GIS software ArcMap 10.2.2, the map of Sardinia vegetal landscape, obtained by information of Sardinia nature map based on the classification of habitat according to CORINE-Biotopes system, have been overplayed with the map of livestock grazing impact map CAIA developed by INTREGA (spin-off ENEA), to obtain for Meriagos (local agro-silvo-pastoral systems; classified "Dehesa 84.6" according to CORINE-Biotopes system), bushlands and woodlands, the surfaces under grazing and evaluate the extension of overgrazing for each of them. Results are reported in the Table 1.

Table 1. Livestock agroforesty area in Sardinia (Italy) and grazing impacts.

\begin{tabular}{|c|c|c|c|c|c|c|c|c|}
\hline \multicolumn{2}{|c|}{ MERIAGOS } & \multicolumn{3}{|c|}{ BUSHLANDS } & \multicolumn{4}{|c|}{ WOODLANDS } \\
\hline $\begin{array}{c}\text { Grazed } \\
\text { surface (ha) }\end{array}$ & $\begin{array}{c}\text { Grazing } \\
\text { impact }\end{array}$ & $\%$ & $\begin{array}{c}\text { Grazed } \\
\text { surface } \\
\text { (ha) }\end{array}$ & $\begin{array}{l}\text { Grazing } \\
\text { impact }\end{array}$ & $\%$ & $\begin{array}{c}\text { Grazed } \\
\text { surface } \\
\text { (ha) }\end{array}$ & $\begin{array}{l}\text { Grazing } \\
\text { impact }\end{array}$ & $\%$ \\
\hline 10.361 & none & 10 & 29.636 & none & 6 & 29.122 & none & 7 \\
\hline 15.726 & negligible & 14 & 43.198 & negligible & 9 & 42.625 & negligible & 11 \\
\hline 18.165 & light & 17 & 48.686 & light & 10 & 43.424 & light & 11 \\
\hline 29.249 & medium & 27 & 88.808 & medium & 18 & 82.712 & medium & 21 \\
\hline 35.183 & high & 32 & 279.956 & high & 57 & 205.437 & high & 51 \\
\hline \multicolumn{2}{|c|}{ Total grazed surface } & \multicolumn{3}{|c|}{ Total grazed surface } & \multicolumn{4}{|c|}{ Total grazed surface } \\
\hline \multirow{2}{*}{\multicolumn{2}{|c|}{$\begin{array}{l}108.684 \\
\text { Total surface }\end{array}$}} & 96 & 490.284 & & 76 & \multicolumn{2}{|c|}{403.319} & 72 \\
\hline & & 10 & \multicolumn{2}{|c|}{ Total surface } & 10 & \multicolumn{2}{|c|}{ Total surface } & 10 \\
\hline \multirow{2}{*}{\multicolumn{2}{|c|}{$\begin{array}{l}112.668 \\
\text { Negrace }\end{array}$}} & 0 & 645.726 & & 0 & 560.984 & & 0 \\
\hline & & & \multicolumn{2}{|c|}{ No grazed surface } & & \multicolumn{2}{|c|}{ No grazed surface } & \\
\hline 3.984 & No grazed surface & 4 & 155.442 & & 24 & 157.665 & & 28 \\
\hline
\end{tabular}

In Sardinia forests lato sensu cover a surface of 1.319 .378 hectares ( $54 \%$ of the total island area), the $8.6 \%$ of which are Meriagos, the $48.9 \%$ bushlands and the $42.5 \%$ woodlands. Fairly 1 million of hectares are grazed ( $76 \%$ of total), with the higher value, obviously, for the Meriagos, and the minimum for the woodlands (72\%). High impact of grazing resulted in more than half of grazed surface ( $521.576 \mathrm{ha}$ ) whit the maximum for the bushlands and minimum for the Meriagos. Data indicate that this productive model represents a great environmental resources for animal production in Mediterranean areas. Consequently, such massive overgrazing my jeopardize the sustainability of these livestock agroforestry systems so that in most area of Sardinia the stocking rate should be reduced.

\section{LOW FREQUENCY ELECTROMAGNETIC FIELDS: RISK ASSESSMENT IN AN OLIVE MILL}

Alexandros Sotirios Anifantis, Simone Pascuzzi, Francesco Santoro

Dipartimento DiSAAT, Università degli Studi di Bari “Aldo Moro”, Italia

\section{E-mail: francesco.santoro@uniba.it}

Key words: electromagnetic fields, olive mill, risk assessment, worker's health.

The risk associated with the presence of low frequency electromagnetic fields $(0 \div 10 \mathrm{kHz})$ is essentially related to the presence of alternate current powered systems and equipment that generates time-varying electrical and magnetic fields. These fields produce, in the human body, potentially dangerous effects which could be evaluated by means of electrical quantities such as electric field magnitude and the internal current density or, more simply, by means of easier to measure quantities such as the effective values of the electrical and magnetic fields present in the environment.

In the olive oil sector, with particular reference to olive mill operations, the extremely low frequency ELF electromagnetic fields $(30 \div$ $300 \mathrm{~Hz}$ ) mainly due to the presence of electrical distribution lines and electric motors operating at a frequency of $50 \mathrm{~Hz}$ are particularly relevant. An experimental analysis aimed at measuring electromagnetic fields in the productive areas of an olive mill recently built in the Bari district was accomplished. The analysis' main goal was to assess the workers' health risk level due to the presence of ELF electromagnetic fields with reference to a specific type of processing plants, widely spread in the Apulia region. A first analysis of the spatial layout of the electric machine was carried out, referring to their duty cycles and to workers' tasks (taking into particular account the working places). This preliminary analysis identified the 12 most significant points in which the measurements of effective value of the electrical and magnetic field would have been carried out. These points are essentially located near the electric motors which drive each operating machine. At these points, for the duration of a full work shift, measurements according to the CEI 211-6 standard instructions for nearfield region were carried out, recording both components of electrical and magnetic fields. The low frequency electric and magnetic fields measurement system used was made by a PMM mod. EHP-50C analyser which complies both to Italian 10/09/98 D.M. 381 and to Italian 07/08/03 DPCM positioned on a non-magnetic tripod. The electric and magnetic field in the frequency range $5 \div 100 \mathrm{~Hz}$, with a $0.25 \mathrm{~Hz}$ scanning interval, for the three components of a global orthogonal Cartesian reference system has been measured in each of the testing points. Effective values of the electric field $\left(E_{R M S}\right)$ as well as effective values of the magnetic induction field $\left(B_{R M S}\right)$ measured in each testing point, obtained whilst taking into account the components along the axes and the whole $5 \div 100 \mathrm{~Hz}$ frequency range examined, were both significantly lower than the limit values required by law. Peak values of both the electric field $\left(E_{\text {peak }}\right)$ and the magnetic induction field $\left(B_{\text {peak }}\right)$ measured in the different testing points at the frequency of $50 \mathrm{~Hz}$, were lower than the corresponding effective values $E_{R M S}$ and $B_{R M S}$. The results of the tests carried out, although within the limits of a preliminary study, highlight that, inside the analysed olive mill, in the period of its maximum productivity, risks for the workers' health related to their exposure to low frequency electric and magnetic fields are not relevant. 


\section{SUSTAINABILITY OF ENERGY USES IN AGRICULTURAL AND FORESTRY SYSTEMS}

\section{ENERGY EFFICIENCY ANALYSIS OF A HYDROGEN AND GEOTHERMAL STAND-ALONE SYSTEM FOR GREENHOUSES HEATING}

Alexandros Sotirios Anifantis, Simone Pascuzzi, Francesco Santoro

Department of Agricultural and Environmental Science (DiSAAT), University of Bari Aldo Moro, Italy

\section{E-mail: alexandrossotirios.anifantis@uniba.it}

Keywords: Renewable energies stand alone system, hydrogen production, ground source heat pump, greenhouses heating.

The current rise of floricultural and horticultural crops in a protected environment, mainly due to market factors and the increase in demand for biological products, is the basis of the significant increase of the energy consumption for the greenhouse climate control. Diesel, LPG and natural gas are generally used as fuel in heating greenhouses and, although the use of renewable energy can improve the sustainability of the crops in a protected environment, these still play a niche role in the energy panorama due to the non-simultaneity of the energy production during the daylight hours compared to the night energy required. For these reasons, the scientific community is aimed at testing new energy storage technologies, such as new batteries with very high efficiency, re-pumping water into elevated water storage systems, boilers powered by solar thermal systems. However, an interesting solution consists in the solar energy conversion in hydrogen $\left(\mathrm{H}_{2}\right)$ in order to implemented a totally renewable and stand-alone system for greenhouse heating.

The above mentioned system was installed at the experimental farm of the University of Bari "Aldo Moro" in order to supply the heating energy required of a experimental tunnel greenhouse of $16 \mathrm{~m}^{2}$. The systems consist of photovoltaic panels connected to an electrolyzer, that during the daylight hours, produce hydrogen by electrolysis and then it is stored in a pressure tank. During the night, thank to a fuel-cell, the hydrogen was converted to electric energy in order to feed a ground source geothermal heat pump for greenhouse heating.

In particular, the system was composed of polycrystalline photovoltaic panels with peak power of $8.23 \mathrm{kWp}$, an alkaline electrolyzer with 2.5 $\mathrm{kW}$ of electric power in the absorption, an hydrogen storage tanks with a capacity of $15 \mathrm{Nm}^{3}$ and operating pressure of 30 bars, a PEM fuel cell with $2 \mathrm{kWp}$ of peak power, buffer gel batteries with a capacity of 10.8 $\mathrm{kWh}$, a heat pump with thermal power of $0.8 \mathrm{~kW}$ and $0.16 \mathrm{~kW}$ of electric absorption and vertical geothermal borehole 120 meters deep.

Considering the energy efficiency of photovoltaic panels of $13 \%$, the energy efficiency of electrolyzer equal to $48 \%$, the fuel-cell energy efficiency of $41 \%$ and finally, the coefficient of performance of geothermal heat pump of 5 , the overall system efficiency, starting from the amount of solar energy available during the daylight hours, was of $12.8 \%$.

\section{GREENDRY: LOW TEMPERATURE DRIER FOR DRYING GRAINS AND OILSEEDS}

Remigio Berruto, Massimo Blandino, Patrizia Busato, Amedeo Reyneri, Alessandro Sopegno, Mario Tamagnone

Università degli Studi di Torino, Dipartimento Scienze Agrarie, Forestali e Alimentari, Grugliasco (TO), Italia

Key words: Low temperature drying, corn, energy saving, logistics, automation.

The natural air/low temperature (NA/LT) in-bin drying technology is not adopted in Italy and Europe. The lack of information and successful examples prevent the diffusion and adoption of this technology by farmers. In the last years, an in-bin drying prototype was developed by the National Institute of Agricultural Technology (INTA) in agreement with four companies in order to investigate the applications of this technology in Argentina. The core of the drying system is a model based fan and burner controller. The system was adapted by DISAFA to be used in Italian conditions and installed in two plant of capacity of 70 and $100 \mathrm{t}$ in NW of Italy to dry corn. The goals of this research were: 1) test the reliability of automatic smart drying controller for low-temperature drying, 2) test the performance of a prototype in-bin drying system for drying corn to $14 \%$ final MC, 3 ) evaluate the energy consumption and 4) evaluate grain quality after drying. The results showed that the in-bin drying system was able to dry the grain in about 28 days from $21.5 \%$ to $13,7 \%$ MC. The individual kernel MC gradient was reduced during drying. The energy consumption was very low compared to traditional mixed flow driers, just about $4.95 \mathrm{~L} \mathrm{t}^{-1}$ of dried grain, equal to $55 \%$ energy saving. Grain quality was very good with very low stress crack index compared to traditional driers. Another important aspect is the very low flow rate of the air compared to traditional driers, that imply practically no dust emissions. These results confirmed the potential of NA/LT in-bin drying systems for drying corn, rice and other special quality grains in NW of Italy.

\section{ENERGY EVALUATION OF GRASS RESIDUES SUPPLY CHAIN FROM NON-CULTIVATED AREAS FOR BIOGAS FEEDING}

Davide Boscaro, Andrea Pezzuolo, Francesco Marinello, Stefano Grigolato, Luigi Sartori

\section{Padova University, Dept. of Land, Environment, Agriculture and} Forestry, Legnaro, PD, Italy

\section{E-mail:davide.boscaro@unipd.it}

Key words: Non-cultivated green areas, anaerobic digestion, harvesting and transport systems, economic and energy analysis

The increasing demand of biomass for biogas production is arousing some concerns about the sustainability of this process. In fact, the cultivation of energy crops in farmlands is becoming more noticeable, causing a competition with food production.

The utilisation of grass from the management of territory as a feedstock for the anaerobic digestion process could contribute to reduce these problems, both on environmental and social aspects. In fact, grass exploitation, beyond minimize the competition with food, could reduce eutrophication and production of greenhouse gases, provide nutrients for the fertilization of the soils and make more profitable the management of landscape and the biogas production.

Although currently grass is not used in the biogas production chain, it is a widely available biomass within the territory. Its anaerobic digestion appears feasible from a functional point of view; nevertheless, there are still few studies related to economic, energy and environmental recovery of this biomass, considering non-cultivated green areas.

The PhD project will investigate about the feasibility of exploitation 
of grass collected in non-cultivated areas for biogas production, examining:

- the available biomass of grass for the anaerobic digestion according to the Veneto region territory;

- the best systems for the supply of anaerobic digestion plants;

- the biochemical methane potential of grass from non-cultivated areas;

- the economic, energetic and environmental advantages or disadvantages of its exploitation.

The results obtained until now reveal different solutions for the cutting, harvesting, transport and storing of grass collected along watercourses. From an economic and energy point of view, the costs are relatively high and variable depending on the organization of the harvesting system, the distances and the transport density. However, several environmental, social advantages, and a better hydraulic safety that the grass harvesting encompasses may be able to compensate the weaknesses encountered.

\section{DEVELOPMENT AND APPLICATION OF A MATHEMATICAL MODEL FOR ENERGY CONSUMPTION OPTIMIZATION IN INTENSIVE SWINE FARMING}

Elena Brundu, Giovanni Chessa, Giuseppe Todde, Djangsou Hagassou, Antonio Pazzona

\section{Dipartimento di Agraria, Università degli Studi di Sassari, Italia \\ E.mail:ebrundu@uniss.it}

Key words: Swine farming, Energy consumption, Sustainability, Device optimization, Algorithm.

Energy saving is a key objective to reduce environmental impact of pig production and to ensure economical sustainability in swine farming. Other than feed consumed by pigs, operating energy includes electricity needed to maintain the pig rearing environment. Copious efforts have been carried out to develop methods for energy system optimization, including the application of newly developed mathematical models. Energy consumption analysis and optimization in animal farming is widespread, but mostly focused on feed rations and recipes. However, electrical energy use in the farm should always be taken into account for economical considerations regarding cost minimization and consequent profit maximization. This work focuses on the optimization of operating electrical energy consumption.

In this study, a mathematical model based on the algorithm principles recently established for a semiconductors manufacturing industry was developed and validated employing the optimization modeling software Lingo 15.0. The model involves three general equations (decisional, calculation, constraints). Experimental data were collected in an energy-intensive swine farm located in Northern Sardinia (Italy) within Sassari province. The main technical features and use time of all equipment involved in the cycle of production were preliminary surveyed, and then the associated monthly and daily energy consumption was determined distinguishing among systems for feeding, lighting, air-conditioning, ventilation, heating, sewage sludge spreading, submerged pump system, and high-pressure jet cleaning. After monitoring all energy-demanding equipment and facilities, the "typical daily consumption", including energy use levels associated with each hour, was defined. Because in our case lighting, air-conditioning, ventilation and heating, represented the majority of swine farming energy consumption costs, only these items were taken into consideration to develop and apply our mathematical model.

Through this application more energy efficient alternatives were identified. Following the results of software analyses, significant savings are achievable for lighting, ventilation, air-conditioning and heat- ing systems. More in detail, in the study farm lighting is based on the use of neon light that can be replaced with led light; air-conditioning system including pad cooling can be improved associating an inverter which allows to achieve around 30\% energy savings; on-off ventilation system can be similarly improved integrating a variable-frequency drive; heating system relies on traditional heat lamps that can be replaced by variable heat lamps whose heat output and consequent consumption are adjusted by a variable voltage controller depending on environmental parameters. These replacements allow significant cost savings (around Euro 8,500.00 annually). Amortization costs of necessary investments, calculated on a 5-year basis, have also been considered to adequately reduce annual savings. Further improvements of this model will provide additional information on its applicability to other kinds of animal farms.

\section{BIOCHAR OBTAINED FROM PELLET OF BIOMASS RESIDUAL BY PYROLYTIC PROCESS IN BATCH}

Andrea Colantoni, ${ }^{1}$ Massimo Cecchini, ${ }^{1}$ Francesco Gallucci, ${ }^{2}$ Alessio Ghignoli, ${ }^{1}$ Francesco Mazzocchi, ${ }^{1}$ Luca Salvati ${ }^{3}$

${ }^{1}$ Department of Agricultural and Forestry Sciences - University of Tuscia, Viterbo; ${ }^{2}$ Consiglio per la ricerca in agricoltura e l'analisi dell'economia agraria (CREA) Unità di ricerca per l'ingegneria Agraria, Monterotondo, Roma; ${ }^{3}$ Consiglio per la Ricerca in Agricoltura e l'Analisi dell'Economia Agraria, Research Centre for Soil-Plant System Studies (CRA-RPS), Rome, Italy

\section{E-mail:colantoni@unitus.it}

Key words: Characterization, biochar, biomass residual, pyrolysis process.

Biochars produced from pellet obtained from grape vine (GV) and sun flower husk (SFH) at different temperature $\left(400\right.$ and $\left.500^{\circ} \mathrm{C}\right)$ were studied after pyrolysis in batch reactor at Bioenergy 2020 Institute in Graz (AU) under the BRISK project.

Chemical and physical evolution of biomass under pyrolysis conditions was determinate and products characterization was evaluated including main organic components in gaseous stream. The objective of this work is to improve the knowledge for alternative use of the biochar obtained from agro-forestry biomass residuals, particularly grape vine and sun flower husks, by means of modern chemical and physical characterization tools.

\section{ENERGY RECOVERY OF HAZELNUT'S PRUNING USING AN IMBERT GASIFIER PROTOTYPE}

Andrea Colantoni, Massimo Cecchini, Leonardo Longo, Lavinia M.P. Delfanti, Ilaria Zambon, Maria Grazia Saporito, Gianluca Egidi, Pierluigi Cavalletti, Danilo Monarca

Department of Agricultural and Forestry Sciences, University of Tuscia, Viterbo, Italy

\section{E-mail:colantoni@unitus.it}

Key words: Energy recovery, Pruning, Gasification process, Hazelnut, Downdraft gasifier.

Aim of this work is to evaluate the possibilities of use of hazelnut pruning as biomass to be used in an Imbert downdraft prototype for gasification with air. Biomass gasification is one of the most used techniques to obtain power from biomass and generally energy crops are used for this scope. In our case is important to stress that hazelnut pruning is a waste management problem and this work highlights that is possible to use pruning for obtaining syngas to power production and a solid residue that could be used as soil improver. In this study bio- 
shredding derived from hazelnut pruning have been characterized to evaluate the energy content that is the most important factor for its use in a gasification process and the LHV obtained is about $15.3 \mathrm{MJ} / \mathrm{kg}$. Syngas obtained show a LHV in a range of 3.84-4.45 MJ/Nm 3 , suitable for power production.

\section{APPLICATION OF 2009/127/EC AND 2009/128/EC DIRECTIVES IN SARDINIA (ITALY): RESULTS ON SPRAYING MACHINES}

Filippo Gambella, Luisella Sistu, Davide Piccirilli, Viviana Guido, Maria Caria, Giuseppe Todde, Giovanni Chessa, Lelia Murgia, Antonio Pazzona

Università degli Studi di Sassari, Dipartimento di Agraria, Sezione di Ingegneria del territorio, Sassari, Italy

E-mail: gambella@uniss.it

Key words: 2009/127/EC, 2009/128/EC, Sardinia, spraying machines.

The use of pesticides in agriculture may affect human health and environment. For that reason, several initiatives were realized in order to lead the proposal of European Commission for a Directive on the sustainable use of pesticides. At European scale the EU Directive 127/2009 amendment of the machinery and EU Directive 128/2009 on sustainable use of pesticides were published. The first one requires as guarantee human and environmental safety the use of EC typeapproval certificate.

The Directive 2009/128/EC was transposed in the Legislative Decree $\mathrm{n}^{\circ} 150$ of 14 August 2012, in that was required the implementation of policies and actions to reduce the risks and impacts of pesticide use on human health and environment (National Action Plan-NAP) at national scale, and in Regional Resolution ${ }^{\circ}{ }^{4} / 62 / 2009$ at local scale (Sardinia).

According to these regional resolution, LAORE agency was involved in the functional control plan realization and in the spraying machines calibration.

In this study were reported the results of the collaboration between LAORE agency and Agricultural Department of Sassari (Land Engineering Section) in "Application of proximal and remote sensing technologies in precision viticulture in Sardinia" project, founded by Regional Law $n^{\circ} 7$ of 7 April 2012.

Preliminary information concerned 115 farms in the Centre and Southern Sardinia, with 115 spraying machines, 25 of them using in viticulture. The major part of those farms joined to the Regional Development Program (RDP), provided in Measure 214 Action 6 "Integrated Production", and have adhered to the functional control of sprayers voluntarily. The $72 \%$ of farmers were informed about 2009/127/EC and 2009/128/EC Directives.

The $68 \%$ of sprayers machines were provided to be CE compliant, on the other hand the $31 \%$ were not CE compliant and in the $1 \%$ of the analyzed farms there were no available data.

Park farm machinery considered were subdivided in three age classes: from 0 to 10 years, from 10 to 20 years and from 20 to 30 years. The first class involved the $36 \%$ of the sprayers, $23 \%$ and $17 \%$ for the second and the third class, respectively, and the remnants $24 \%$ was unavailable. Moreover, the most frequently problems that not complied with the role concerned: the gauge pressure typology, the inadequate nozzles, the possibility to read the liquid level in the main tank, command module positioning and the irregular rate flow emissions.

\section{ADDING VALUE TO VINE PRUNING RESIDUES: AN ENERGY SUSTAINABILITY ANALYSIS}

Gubiani Rino, Pergher Gianfranco, Dell'Antonia Daniele, Cividino

Sirio, Rossano Secondo, Paciotti Paolo

Università degli Studi di Udine Dipartimento di Scienze

Agroalimentari, Ambientali e Animali, Udine, Italy

Key words: LCA, vine shoots, energetic sustainability, harvester yards.

The objective of this study was to analyse the energy balance of different supply chains based on harvesting of vine pruning residual for combustion in biomass heating plants. During winter 2014 several harvesters were tested, including big balers, small balers, and choppers delivering the material either in bags or in a tank. Wood chips were used directly, while the bales were chopped at the moment of feeding them into the combustion plant. One part was used directly in the heater and another part was transformed in pellet. This biomass will be used for burning in a heater in an existing center for drying wood and cereals. After calculating the cumulative energy demand (CED), this value was compared with another fuel as diesel oil, adopting the LCA (Life Cycle Assessment) methodology. The energetic sustainability of the vine residues supply chain is a priority for evaluating the possibility to use this material as a fuel. The data for the comparison of energy balances of diesel fuel and biomass were input in a database (Ecoinvent v.2) inside the software SimaPro 7.2.4. For the output values, data from the literature was used. For evaluating the efficiency of the biomass supply chain we used the EROI (Energy Return On Investment) index. This index is calculated as the ratio of energy in final product after burning to the energy consumption during the whole production process. The results showed that the vine residues supply chain is more convenient if chips are harvested and directly burned; the small-baler and big-baler alternatives were more expensive. Direct use of wood chips resulted in a better EROI index than the EROI index for the harvesting with balers with subsequent pelletization. Of course the pellet can be commercialized better than the chips. The evaluation of energetic sustainibility of the supply chains for harvesting of winter pruning residuals in the vineyard showed than both supply chains for production of chips and pellet were sustainible, with EROI indexes between 5.5 to 16.4 for chips and between 4.5 and 10.2 for pellet production. By comparing the EROI indexes of biomass and diesel fuels we found a high convenience to use the biomass; in fact, the diesel had an EROI index of 0.7, remarkably smaller than those obtained from both chips and pellet.

\section{ENVIRONMENTAL AND ECONOMIC BENEFITS DUE TO SUBSTI- TUTION OF TRADITIONAL COOKING STOVES IN MOZAMBIQUE}

Antonio Guiso, Lorenzo Guerrini, Lenin Javier, Ramirez Cando, Paolo Spugnoli

GESAAF, Università degli Studi di Firenze, Italy

E-mail: antonio.guiso@unifi.it

Key words: Cooking Systems, Climate Change, Deforestation, Soil Organic Carbon.

Around 3 million people in the world use solid biomass such as wood and charcoal for cooking. These materials are mostly used to fuel traditional and inefficient cookstoves. Emissions derived from inefficient biomass burning have an important impact on climate change (IPCC, 2014) and human health (around 4.3 million premature deaths per year caused by indoor pollution, WHO, 2013). Direct impact involves as well forest degradation and the charcoal purchasing costs sustained by the families. This study provides a mitigation potential analysis of these impacts after the replacement of traditional charcoal cookstoves with 
more environmentally efficient cookstoves in one area of Maputo, in Mozambique. Fuel consumption reduction has been estimated using a data collection campaign in the project area. 150 families have been randomly chosen to participate from a total of 1063 families involved in the project. Fuel consumption of each family has been measured during three days before and during three days after the introduction of the new stoves. The results show that daily fuel consumption has decreased from $2,57 \mathrm{~kg}$ to $0,53 \mathrm{~kg}$ per day and family. The total carbon emission reduction has been estimated in 627 tons in all the project area. Whereas charcoal emission factor (IPCC, 2006) is 18,58 tons of C02 equivalent per ton of fuel, the use of efficient stoves results in gas emissions reduction of around 12,466 tons of $\mathrm{CO} 2$ equivalent per year. The charcoal emission factor used in this study considers the full life cycle, including the amount of wood necessary for producing the charcoal. Charcoal production processes are extremely inefficient in Mozambique and the ratio from charcoal to wood is of $1 / 6$. Considering that the average quantity of biomass available per hectare in Miombo forests in Mozambique, the usual supply area, is of 50,5 tons per hectare, the reduction in charcoal consumption, as a result of efficient stove use, results in a forest cutting reduction of 13 hectares. However, the charcoal emission factor used in this study does not include the loss of organic carbon from soil caused by deforestation, which has been estimated at around 53 tons of $\mathrm{CO} 2$ per hectare. In addition, the use of environmentally efficient stoves has also important economic effects for local families, each of which saving approximately $168 \$$ yearly. This study represents the first phase of a wider research project in which the analyses are to be extended to other areas of Mozambique and other fuel supply chains. We do not include here data on the direct effects on human health, as this is the aim of an on-going monitoring campaign on indoor and production areas air

\section{ENERGY AND ENVIRONMENTAL ANALYSIS OF CHAINS FOR HORTICULTURAL PRODUCTS BELONGING TO I, III, IV GAMMA}

Alessio Ilari, Daniele Duca, Ester Foppa Pedretti, Giuseppe Toscano

Department of Agricultural, Food and Environmental Sciences, Marche Polytechnic University, Ancona, Italy

E-mail: a.ilari@pm.univpm.it

Key words: LCA, Agro-food, Sustainability, Production chain.

Within the agricultural world, the horticultural sector is currently considered as one of the largest contributors in terms of environmental impact. This is due, mostly, to the intensity of soil cultivation and the use of crop inputs. Currently, processed horticultural products, mainly frozen and "ready to use", are becoming very popular, thanks to usability and availability on the market and to the fact that they are well matched with the growing frenzy of human activities. From a wider point of view, I, III, IV, gamma products require elaborate and energivorous equipment for processing, with which could be associated an even greater risk of environmental impact. The overall sustainability analysis of food chains is therefore an essential goal. The life-cycle assessment methodology (LCA) IS0 14040:2006, 14044:2006 has been applied to some important products considering two medium agro-food enterprises of Marche region. Through questionnaires, surveys and database elaboration, energy and material flows throughout the production chain have been detected. The production chain steps analysed have reference to: production of propagation material in nurseries; transportation into the field; cultivation; transportation and processing to plant. The analysed products include fresh and "ready to use" salads and frozen vegetable III gamma products. SimaPro ${ }^{\circledR}$ v.8.1.1. software for impact assessment has been used. The results obtained offer a plurality of uses ranging from knowledge of the process impact level to the detection of steps with higher associated impact, information usable as base for other studies in the same sector or as comparative data. Other possible uses are those related to the assessment of any mitigation measures, aimed at increasing the energy, environmental and economic efficiency of the production process.

\section{THE MA_S_LO_WAT_EN PROJECT (HORIZON 2020) MARKET UPTAKE OF AN INNOVATIVE IRRIGATION SOLUTION BASED ON LOW WATER-ENERGY CONSUMPTION}

Antonio Pazzona, ${ }^{1}$ Luigi Ledda, ${ }^{2}$ Claudio Zucca, ${ }^{1}$ Lelia Murgia,,${ }^{1}$ Filippo Gambella, ${ }^{1}$ Paola Deligios, ${ }^{2}$ Anna Maria Urgeghe, ${ }^{1}$ Davide Piccirilli, ${ }^{1}$ Viviana Guido,${ }^{1}$ Maria Caria, ${ }^{1}$ Giuseppe Todde, ${ }^{1}$ Mario Antonello Deroma, ${ }^{1}$ Salvatore Madrau ${ }^{1}$

${ }^{1}$ Università degli Studi di Sassari, Dipartimento di Agraria, Sezione di Ingegneria del territorio, ${ }^{2}$ Sezione di Agronomia, Coltivazioni erbacee e Genetica (SACEG), Sassari, Italia

\section{E-mail:pazzona@uniss.it}

Key words: photovoltaic pump, irrigation, ICT

Agricultural irrigation is a highly consuming activity of electricity (24,000 GWh/year in Southern Europe) and, of course, of water $(70,000$ $\mathrm{Mm}^{3} /$ year). In the last years the price of electricity has increased dramatically (for example, in Spain 1250\% from 2008 to 2013 for Irrigators Communities, in Portugal $226 \%$ and in Italy $32 \%$ ), reducing the competitiveness of many agriculture productive initiatives. Moreover, the environmental impact associated to the scarcity of water is a major EU concern. In fact, in some areas of the Mediterranean cost, the water table falls 10 meters per year and it is already at $250 \mathrm{~m}$ deep. This is not the only environmental problem associated to productive irrigation. It is estimated that the $\mathrm{CO}_{2}$ emissions due to the consumption of electricity from fossil sources are more than 16 millions of tons of $\mathrm{CO}_{2}$, with a great impact in one of the major concerns of EU society: the climate change. The world of irrigation requires innovative solutions, less water and energy dependent, to face up this problem. MASLOWATEN project, funded from the European Union's Horizon 2020 research and innovation programme, under grant agreement No640771, will contribute to fill this gap. MASLOWATEN includes big companies in its consortium with enough capacity for the exploitation of the innovative solution. The consortium is led by the UPM (The Technical University of Madrid) and is composed of 13 members from different fields - irrigation communities, research, business, universities - from five European countries. The University of Evora, Portugal, and the University of Sassari, Italy, are among the partners. The general objective of MASLOWATEN project is the first application and market replication of a new green product consisting of Photovoltaic (PV) pumping systems for productive agriculture irrigation consuming zero conventional electricity and $30 \%$ less water. The solution makes this integration using automatisms, Information and Communications Technology (ICT) solutions and precision agriculture techniques. The cost reduction linked to the large-scale PV pumping systems will incentive the use of the systems for efficient use of water. Solar irradiation, wind and rain prediction are integrated in the PV systems. The control of electric valves and the measurement of the water supplied, automatic and simplified, guarantee the reduction of the irrigation water consumption. Soil humidity sensors are used to determine crop needs, by adopting precision agriculture techniques that consider the spatial variability of soil properties. The solutions are implemented in the following demonstrators: Cooperative "Estrella de San Juan", Alaejos (Spain) devoted mainly to the cultivation of beetroots; Farm "Sarciofo", Uri, Sardinia (Italy), devoted to the cultivation of artichoke; Farm "Sao Barnabé", Alentejo (Portugal) and Farm "Soprolives", in Tamelelt (Morocco), both devoted to the irrigation of olive trees. 


\section{ENERGY EFFICIENCY EVALUATION OF THE ENGINES FITTED ON AGRICULTURAL TRACTORS THROUGH OECD DATA}

Domenico Pessina, Davide Facchinetti, Davide Giordano

Department of Agricultural and Environmental Sciences, University of Milan, Italy

E-mail: domenico.pessina@unimi.it

Keywords: tractor, OECD tests, specific consumption, energy efficiency.

Sustainability in agriculture must necessarily take into account also the energy efficiency of self-propelled machinery, first of all tractors. The engine efficiency (i.e. the reciprocal of the specific fuel consumption) is widely known as the most important factor affecting the general performance of the machine.

Over the past 20 years, the standards relevant to the pollutant content of the gas emissions of internal combustion engines have had a remarkable effect (either positive or negative) on the technical development of the engines fitted on tractors and other self-propelled agricultural machines. Unfortunately, in some cases the application of dedicated devices and/or the setting of some running parameters did not allow a suitable reduction of the specific consumption (i.e. an improvement of the overall efficiency) expected from the natural evolution of the engine design and manufacturing.

Under the OECD (Organization for Economic Cooperation and Development) umbrella, over the last past decades a well established network of Testing Stations carried out all over the world several tests to check the performance of agricultural tractors, according to the codes specifically developed, and above all constantly updated in relation to the technical progress.

This situation lead to the creation of a huge database continuously enlarged and updated, useful to focus, among other aspects, the evolution of the technical performance of the engines mounted on agricultural tractors.

The Department of Agricultural and Environmental Sciences of the University of Milan is one of the Testing Stations officially enabled to the application of some of the OECD Codes, and has access to the data included in the test reports. With reference to the last 15 years, a careful and thorough analysis of the tractor engines performance was therefore carried out. After a preliminary classification of the construction characteristics of the engine (number of cylinders, capacity, turbocharger and anti-pollution devices fitting, etc.), the tractors (and their engines) have been divided by power classes and analyzed regarding the specific fuel consumption (i.e. their efficiency), carefully considering the different operating conditions provided by the testing protocols. In fact, the OECD Code 2 commendably does not provide only the recording of the absolute minimum specific consumption value, but also the ascertainment of those obtained in much more running situations, at partial load and speed value, to verify the engine efficiency in the most probable and frequent tractor working conditions. For each tractor power class, some working scenarios have been created (differing for the typical operations carried out and therefore the engine load), in order to highlight the most realistic energy efficiency of the engine. These results should appear more useful than the absolute minimum value of specific fuel consumption, which refers to an engine running condition usually not achieved in the common agricultural operations.

\section{N-TRE: NARROW TRACTORS REAL EFFICIENCY}

Domenico Pessina, Davide Facchinetti, Davide Giordano

Department of Agricultural and Environmental Sciences, University of Milan, Italy

E-mail: domenico.pessina@unimi.it

Keywords: tractor, specific fuel consumption, energy efficiency.

A complete and reliable evaluation of the agricultural tractor performance should provide the ascertainment of many parameters. The diesel engine is the only power source on the tractor, and therefore in the past much attention was focused exclusively on it.

Some methods were recently set up to assess the efficiency of utility and high power tractor models, when working during usual operations. On the contrary, narrow-track tractors used in vineyards, orchards and in green areas have not yet been evaluated properly with such methods. Nevertheless, given the considerable economic impact of the special crops, the narrow-track tractors have always played and still play a key role in the Italian market panorama, for the large number of working machines, but above all for the leading positions of the Italian manufacturers in the world market.

This work is aimed to obtain one (or few) indicator(s) of the narrow tractors willingness to be used with high efficiency in many different operating conditions.

From the performance point of view, particular attention has been devoted to the specific fuel consumption and to the power developed at the PT0, through the hydraulic system and in terms of drawbar pull, also at partial loads. The most probable use scenarios of the narrow tractors were simulated, by setting 3 different levels of power development (low, medium, high). The results are expressed in terms of energy efficiency, by means of numbers or equivalent symbols commonly used in other technical fields (i.e. colour code).

\section{EVALUATION OF DIRECT ENERGY INTENSITY AND RELATED ENVIRONMENTAL LOAD IN CONVENTIONAL AND ORGANIC DAIRY FARMS}

Giuseppe Todde, Lelia Murgia, Maria Caria, Filippo Gambella, Antonio Pazzona

\section{Dipartimento di Agraria, Università Degli Studi di Sassari}

E-mail:gtodde@uniss.it

Key words: diesel, electricity, $\mathrm{CO}_{2}$ emissions, milk

Sustainability and environmental impact of intensive agricultural productions are among the most debated issues in the last years. In this context, organic farming is generally considered more environmental friendly and sustainable than conventional farming systems.

The objectives of this study were to assess the direct energy intensity in organic and conventional dairy farms, to identify the allocation of energy usages among the different on-farm operation and to evaluate the emission of carbon dioxide associated to the energy usage.

The survey involved 4 conventional (CF) and 4 organic dairy farms (OF) located in California, USA. Data on general farm characteristics, equipment and machinery, milk production and energy consumptions (diesel and electricity) were collected with reference to one year of operation. A detailed auditing was done to allocate the direct energy consumptions among the diverse on-farm activities. Farm's energy efficiency was calculated as index of energy used (EUI) per unit of herd size or milk produced.

The average herd dimension of $\mathrm{CF}$ was 3,424 cows, more than 3 times the size of the organic ones (1,005 cows). The milk yield was on average12.2 tonnes of FPCM per lactating cow in CF and 7.12 in OF. The 
annual energy consumption in CF amounted on average to $145,756 \mathrm{~kg}$ of diesel fuel and 1,046 MWh of electricity, while OF showed a lower request, $49,467 \mathrm{~kg}$ of diesel and 449,791 $\mathrm{kWh}$ of electricity.

However, observing diesel EUIs, results underline higher fuel consumption per head and $\mathrm{kg}$ of milk in OF compared to CF, but lower consumption when referred to unit of cultivated area. The electricity EUIs for CF were $293 \mathrm{kWh}$ per head and $0.043 \mathrm{kWh} \cdot \mathrm{kg} \mathrm{FPCM}^{-1}$, lower than those calculated for OF, $860 \mathrm{kWh} \cdot \mathrm{head}^{-1}$ and $0.189 \mathrm{kWh} \cdot \mathrm{kg} \mathrm{FPCM}^{-1}$.

Irrigation was the most demanding operation in both groups of farms, requiring $31 \%$ and $76 \%$ of the annual electricity consumption in $\mathrm{CF}$ and $\mathrm{OF}$, respectively. Other processes that contributed significantly to the electricity requirements in CF were: slurry management (15\%), lighting (14\%), milk refrigeration (10\%), milking and feed management ( $9 \%$ each). Electricity requirements in OF showed a wide differ- ence: milking accounted for $12 \%$, lighting $4 \%$, milk refrigeration $3 \%$ and slurry management $3 \%$ of total consumption.

The largest diesel consumptions associated to farm and field processes in $\mathrm{CF}$ were feed preparation and distribution (71\%) and crop cultivation (25\%), while in OF they were land cultivation (55\%) and feeding operations (40\%).

The average annual emissions, due to all energy usages, in CF was $394 \mathrm{~kg} \mathrm{CO}_{2}$-eq per lactating cow and $0.0322 \mathrm{~kg} \mathrm{CO}_{2}$-eq per $\mathrm{kg}$ of FPCM. These values resulted higher in $\mathrm{OF}$ where the use of fossil energies was estimated to emit $628 \mathrm{~kg} \mathrm{CO}$-eq per lactating cow and $0.0958 \mathrm{~kg}$ $\mathrm{CO}_{2}$-eq per $\mathrm{kg}$ of FPCM.

Type of farm management and milk yields highly influence the efficiency of direct energy usages in dairy production, particularly in organic systems. 


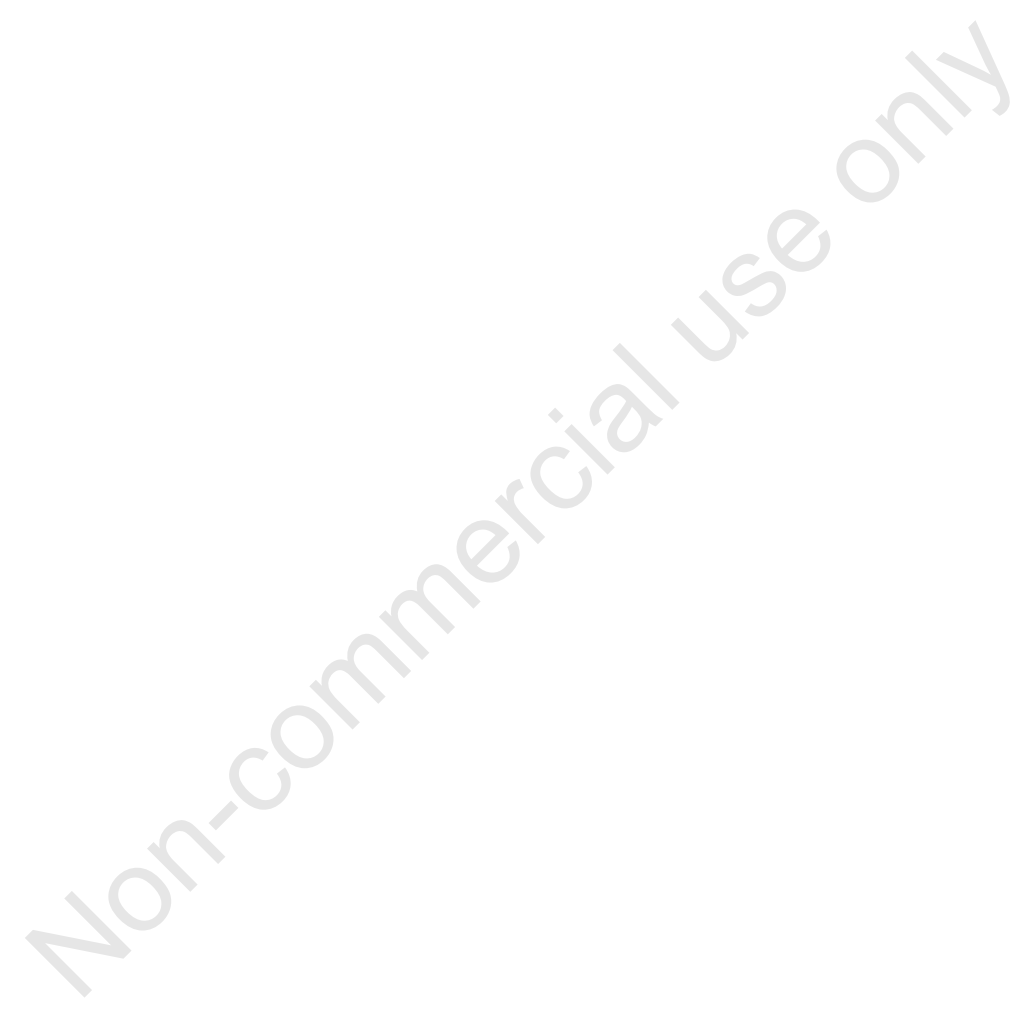




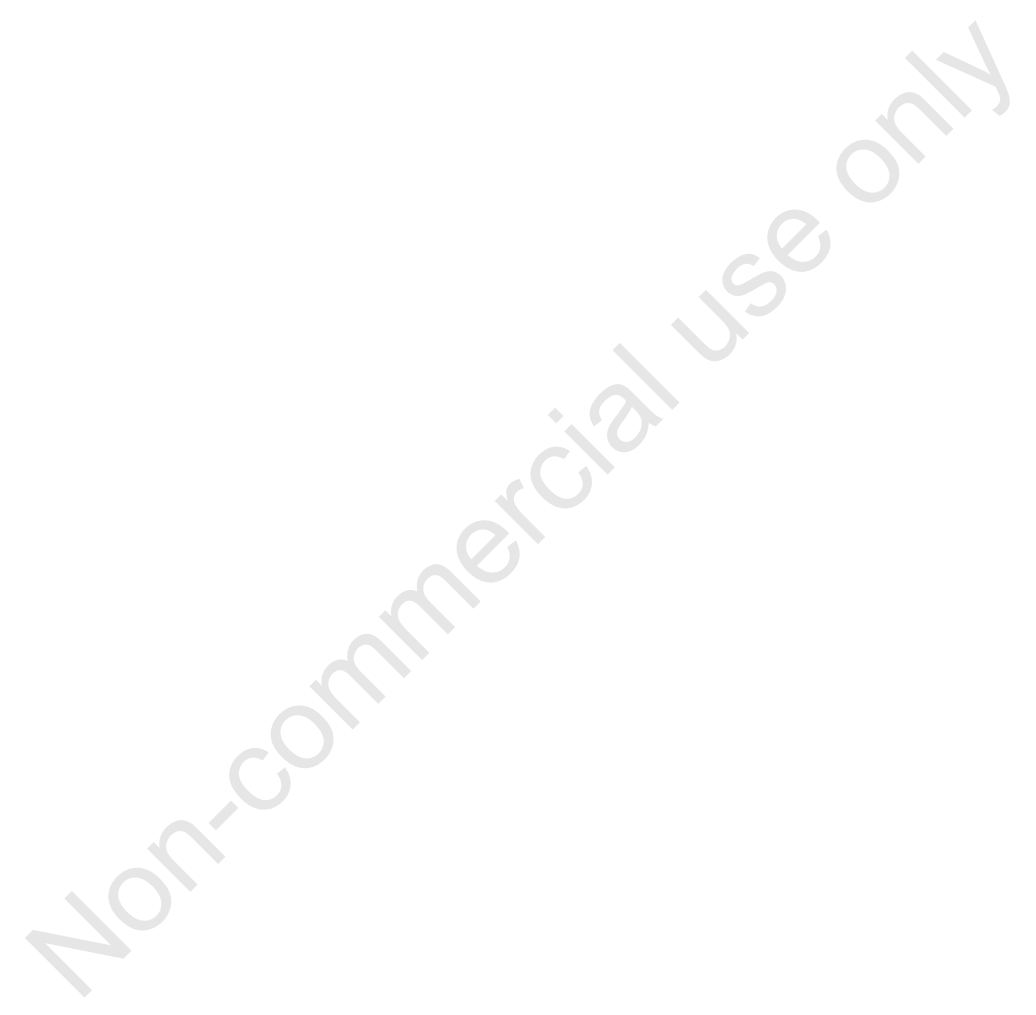


